\title{
Working
}

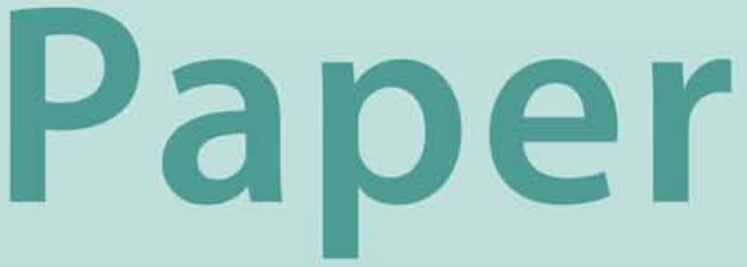




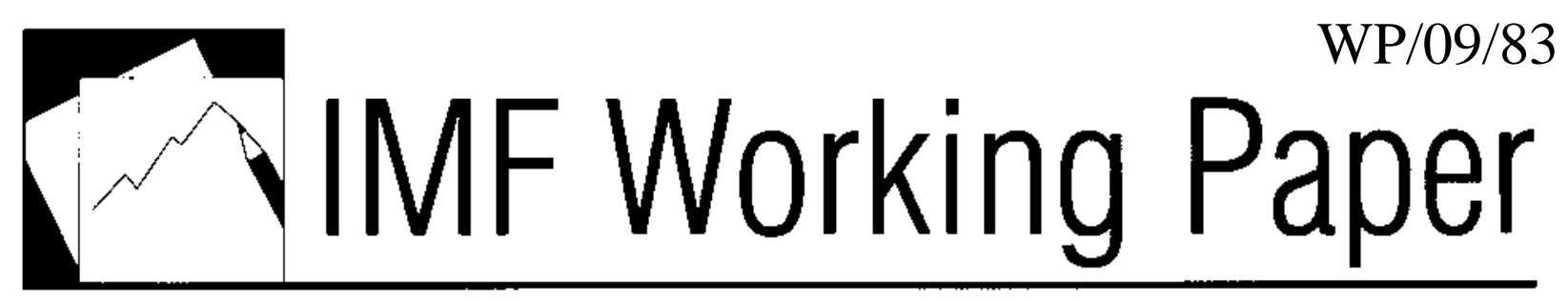

\section{Hold Your Nose and Vote: Why Do Some Democracies Tolerate Corruption?}

Marco Pani 


\title{
IMF Working Paper
}

\author{
Middle East and Central Asia Department \\ Hold Your Nose and Vote: \\ Why Do Some Democracies Tolerate Corruption?
}

\author{
Prepared by Marco Pani ${ }^{1}$
}

Authorized for distribution by Domenico Fanizza

April 2009

\begin{abstract}
This Working Paper should not be reported as representing the views of the IMF. The views expressed in this Working Paper are those of the author(s) and do not necessarily represent those of the IMF or IMF policy. Working Papers describe research in progress by the author(s) and are published to elicit comments and to further debate.

This paper analyses why corruption can persist for long periods in a democracy and inquires whether this can result from a well-informed rational choice of the citizens. By applying a citizen-candidate model of representative democracy, the paper analyzes how corruption distorts the allocation of resources between public and private expenditure, altering the policy preferences of elected and nonelected citizens in opposite directions. The result is a reduction in real public expenditure and, if the median voter's demand for public goods is sufficiently elastic, a tax reduction. In this case, some citizens can indirectly benefit from corruption. The paper shows that, under this condition, if the citizens anticipate a shift in policy preferences in favor of higher public expenditure, they may support institutional arrangements that favor corruption (such as a weak enforcement of the law) in order to alter future policy decisions in their favor. This result complements the findings of other studies that have attributed the persistence of corruption in a democracy to some failure on the part of the voters or the electoral system. It also bears implications for developing effective anticorruption strategies and for redefining the role that can be played by the international community.
\end{abstract}

JEL Classification Numbers: $\quad$ D72; H20; H41; H50; K40; K42.

Keywords: Corruption; Political Equilibrium; Public Goods; Public Expenditure; Constitution.

Author’s E-Mail Address: MPani@imf.org

\footnotetext{
${ }^{1}$ I am grateful to Reza Baqir Amrita Dhillon, Domenico Fanizza, Clive Fraser, Giovanni Ganelli, Carlo Perroni, Peter Sinclair, and participants at a seminar at the INS Institute for comments and suggestions, and to Estefanía Fallas and Margaret Griggs for their valuable editorial help. Any remaining errors are my responsibility.
} 


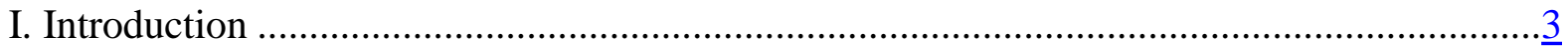

II. Relations with Previous Studies............................................................................

III. A Model of Public Expenditure with Corruption ........................................................ $\underline{6}$

A. How ministers respond to corruption: honest and corrupt citizens.......................... $\underline{9}$

B. The political response of non-elected citizens ...................................................

C. The choice between honest and corrupt candidates .............................................

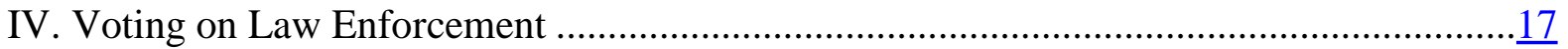

A. Law enforcement and policy choice ..........................................................

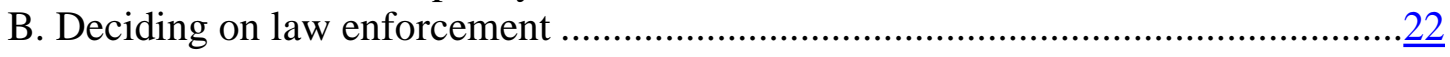

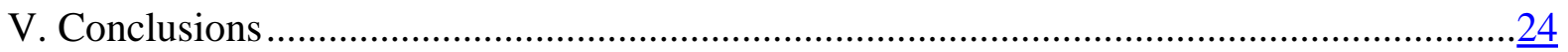

Appendix: Proofs of Propositions ...........................................................................

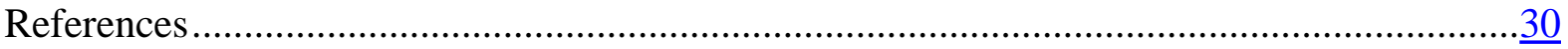


He was a pirate with a tremendous and sanguinary history; and as long as he preserved unspotted, in his retirement, the dignity of his name [...] homage and reverence were with him high and low; but when at last he descended into politics and became a paltry alderman, the public "shook" him, and turned aside and wept. When he died [...] little by little he has come into respect again; but it is the respect for the pirate, not the alderman.

Mark Twain, Life on the Mississippi.

\section{INTRODUCTION}

Controlling corruption remains a major challenge in democratic countries. In principle, public control and accountability should induce public officials in a democracy to be honest (Treisman, 2000), but historical experience shows that democracy by itself does not guarantee that corruption will not becoming entrenched. Well-known examples of democracies that have experienced long high-corruption periods include Italy, Japan, India, and the United States between the Civil War and the Great Depression. The importance of the problem cannot be underestimated: corruption is socially wasteful, harmful to growth (Mauro, 1995; Tanzi and Davoodi, 1998; Del Monte and Papagni, 2001), diverts resources to unproductive rent-seeking efforts, distorts incentives, increases inequality and poverty (Gupta et al., 2002), and prevents effective management of public expenditure. A country that fails to control corruption suffers substantial welfare losses. Aware of these problems, multilateral organizations like the IMF or the World Bank are intensifying their efforts to promote governance and combat corruption.

The political economy of corruption has been widely discussed in the literature, but some issues have not been fully resolved. For instance, the persistence of corruption is frequently explained in terms of some failure either on the part of the voters (apathy, asymmetric information) or of the democratic mechanism (shortcomings of the electoral system). Is corruption always the result of some defect, or can it arise also in a well-functioning democracy? Understanding this issue may be important for designing effective anticorruption strategies.

This study examines whether corruption can also persist in a well-functioning democracy in which fully informed citizens make rational decisions. More specifically, this study analyzes how corruption alters the way in which individual preferences are aggregated into collective choices by representative democracy, and how this impact can motivate the maintenance of institutional arrangements that encourage some agents to engage in corruption.

Using a simplified version of Osborne and Slivinski's (1996) “citizen-candidate” model, we analyze a situation in which corruption distorts the allocation of resources between private and public goods, inducing the citizens to reduce demand for the latter. While the majority always suffers from this distortion, a minority may indirectly benefit if this entails tax reductions. In this case, if the current majority expects to become a minority in the future, corruption can be strategically used to induce the future majority to impose lower taxes. In 
this sense, decisions concerning law enforcement, accountability, and other institutional variables that affect future incentives to engage in corruption bear similar effects to decisions to amend the constitution: both types of decisions set long-standing parameters that condition future short-term policy choices and are, to some extent, made taking these effects into consideration.

Under these circumstances - and in particular when the citizens expect a future change in preferences in favor of more taxes and more public expenditure-corruption can arise even in a well-functioning democracy. In other situations, corruption may not actually occur, but its threat (arising from distorted incentives and weak law enforcement) can affect the policy choice by altering the outcome of free and fair elections. These results can bear important implications on how the international community conducts its fight against corruption.

The rest of the paper is organized as follows: Section II discusses how this paper builds on three different strands of research that have examined the political economy of corruption, the principal-agent relation inherent in corrupt transactions, and the impact of corruption on public expenditure. Section III introduces a model of political choice in which corruption distorts the decision of the elected representatives in a way that is fully predictable and discounted by the voters; it shows how, once elected, candidates respond to corruption based on their policy preferences and the risk of punishment; the section also discusses the anticipatory response of the nonelected voters. Section IV extends this model to incorporate a collective decision on the appropriate degree of law enforcement, which has a predictable impact on future policy decisions; it shows that under certain conditions citizens vote in favor of weak law enforcement, thus encouraging corruption. Section V draws some brief conclusions and suggestions for further research.

\section{Relations With Previous Studies}

This study builds on three different strands of research that have analyzed corruption in terms of political economy, agency theory, and the impact of corruption on public expenditure.

A series of studies have analyzed the political economy of corruption in democracy. These studies have generally linked corruption to failures in the functioning of the democratic system such as informational asymmetries between voters and candidates, lack of interest ("apathy”) on the part of the voters (Rose-Ackerman, 1978), or a lack of honest candidates with policy preferences close to those of the majority (Rundquist et al., 1977; Kurer, 2001). Several studies have traced corruption to shortcomings of the electoral system such as the political fragmentation that emerges under proportional representation (Myerson, 1993; Galeotti and Merlo, 1994; Persson et al., 2003). The literature on lobbying and interest groups (Becker, 1983; Grossman and Helpman, 1996) has analyzed how corruption can be used to distort the democratic process to serve the interests of particular groups.

However, these studies do not fully explain how corruption can persist when it is widely perceived to be causing severe welfare losses. Under pressing needs, in democracy, voters should eventually become more interested in the political process and overcome initial 
informational asymmetries; new candidates with a reputation for honesty and more varied policy preferences should challenge the corrupt incumbents; and more forceful action should be taken to counter the pressure of special interest groups. If corruption were caused by inadequacies in the electoral law, the law itself could be changed, as occurred, for instance, in Italy in the early 1990s. Some studies (Treisman, 2000; Calderon and Chong, 2006) have actually found evidence that democracy curbs corruption in the long run.

Our model contributes to this line of research by further exploring the causes of corruption in a democracy but, unlike previous studies, focuses on a well-functioning democracy in which citizens are interested and well informed and candidates of all political inclinations are always available. We assume that the electoral system aggregates efficiently the preferences of the citizens, and model it by using a simplified "citizen-candidate” model (Osborne and Slivinski, 1996) in which any citizen can stand as a candidate and the candidate who is elected is the one who cannot be defeated in a pairwise contest by any other candidate. As in Rose-Ackerman (1978), we feature an elected representative who trades off bribes against some risk (in her case, losing votes; in ours, being punished by law). Voters also face a tradeoff, between honest candidates with less-preferred policy preferences and corrupt candidates that are politically closer. Unlike in Peters and Welch (1980), however, this trade-off does not arise because the set of candidates is limited but because the propensity to engage in corruption is correlated with a candidate's policy preferences. Contrary to models of special interest groups, bribes are not aimed here at influencing policy decisions but are used for mere personal greed. This allows to put in evidence some other aspects of corruption: corruption does ultimately affect the policy outcome and can also be used deliberately to this purpose by a large group of citizens that do not directly take part in corruption. RoseAckerman (1999) also discussed a situation in which corruption is supported by a large number of citizens who do not take part in it, but their aim was still to divert public resources to serve particular individual interests. In our model, public resources are always used for their proper public purpose, but citizens have different preferences about the amount of resources that should be allocated to public use, and these differences can potentially give rise to corruption.

Applied to the study of corruption, agency theory has shown in some detail how corruption can be tolerated as a result of an informed, rational choice when controlling it is costly (Basu et al., 1992; Chander and Wilde, 1992; Hindricks et al., 1999). These studies, based on Becker's seminal work on the economics of crime (Becker, 1968), generally assume a welldefined objective function (such as maximizing tax revenue net of collection costs) and abstract from the problems of of the aggregation of preferences.

Arguably, the high degree of corruption observed in some democracies is hard to reconcile with an informed welfare-maximizing decision on the part of the voters, even when taking into account the high costs of controlling corruption; over time, improvements in the anticorruption "technology" (including a better understanding of its institutional aspects) should reduce these costs, and corruption should decline. The outcome can change, however, if individuals have different policy preferences and try to use corruption to impose their preferred policy choice on the rest of the community. Our model examines this case by 
applying the incentive structure discussed in previous studies to a setting in which individual preferences are aggregated by representative democracy.

The impact of corruption on public expenditure has been discussed from various angles in previous studies. Barro (1973) analyzed how corruption induces elected public officials to increase public expenditure, while other authors (such as Dudley and Montmarquette, 1987, or Ades and Di Tella, 1997) discussed how corruption alters the policy preferences of nonelected citizens. Mauro (1998) found empirical support to the argument that corruption diverts public expenditure toward items "on which it is easier to levy large bribes and maintain them secret."

This a central theme in our model because the citizens' response to corruption depends critically on how corruption alters the allocation of resources between public and private uses (although our model can be extended to include the impact of corruption on a more general set of policies). Our model bears some similarities to Barro's, with the notable differences that, in our model, citizens do not have a tendency to reelect the incumbent but vote to maximize their expected utility, and their policy preferences depend on whether or not they expect corruption to occur. While corruption induces the elected representatives to increase expenditure in order to get more bribes, the citizens respond by electing candidates with different policy preferences (if not more honest). The net impact on the volume of public expenditure is negative, but the impact on its value is ambiguous. Applied to the problem discussed in Mauro (1998), our model would yield somewhat different predictions.

\section{A Model of Public Expenditure With Corruption}

There are two types of goods, a pure private "consumer good" (unspecified) used individually by each citizen, and a pure public good, "roads," ${ }^{2}$ which can be used jointly by all citizens without rivalry or congestion. Both goods are produced by a competitive sector of enterprises with a common technology that exhibits constant marginal costs (normalized to one). The consumer good is sold directly by the enterprises to consumers, but roads cannot be purchased by individual consumers directly owing to free-rider problems; instead, the producers sell them to a common representative (the "minister"), who makes them available to all citizens. Roads can be supplied in different amounts, but, once purchased by the minister, they are available to everybody in their entirety. ${ }^{3}$

\footnotetext{
${ }^{2}$ The word "roads" is used only to simplify the narrative. In reality, roads are not "pure” public goods, they are excludable (through tolls) and subject to congestion. Nevertheless, ,they are frequently built by private contractors and then transferred to the government for public use by all citizens; and can be supplied in different amounts.

${ }^{3}$ The network of roads, for instance, can vary in extension and coverage, but it is open to all users in its entirety. Each potential user benefits to some extent from the whole extension of the road network even if he uses only part of it.
} 
The minister pays for the roads with funds collected from the citizens through income taxes. To abstract from redistributive effects, it is assumed that all citizens receive the same gross income (normalized to one) and pay the same taxes. All the tax revenue is used to pay for road construction, and all income net of taxes is spent on the purchase of consumer goods: there are neither credit nor savings, neither public nor private. ${ }^{4}$

The citizens have different preferences concerning the allocation of resources between roads and consumer goods. Their utility function is quasi-linear in consumer goods, and differs by a preference parameter $\theta$, which captures the intensity of each citizen's utility from roads; $\theta$ identifies the "type" of each citizen:

$$
U(x, g ; \theta) \equiv x+\theta u(g)
$$

where $x$ is the individual consumption of consumer goods, $g$ is the quantity of roads available to all citizens, $\theta>0$ is the citizen's type and $u(\bullet)$ is a continuous, concave, and twice differentiable function that is common to all citizens (in Section III, to enhance tractability, it is further assumed that $u(\bullet)$ is three times differentiable with $u$ " ' $\geq 0$ for all $g>0){ }^{5}$ Types are distributed among the population according to a cumulative distribution function $F(\theta)$, which is common knowledge. It is assumed that the set of types is dense, but the results of this paper can be generalized to nondense (and even discrete) sets of types.

Each citizen pays a tax equal to $t$; total tax revenue is equal to $t n$, where $n>1$ is the size of the population. ${ }^{6}$ The public budget constraint requires that tax revenue equals public expenditure, which is in turn equal to $g$; hence, $t=g / n$. The allocation of income between consumer goods and roads (through taxes and the public budget) is the same for all citizens and is hereafter called a "policy." Since $n$ is given and the public budget constraint is binding, a policy can be identified either by the tax rate $t$ or by the supply of roads $g$ (but using the latter yields simpler formulas). Given $g$ (and $t$ ), the private budget constraint requires that $x=1-t=1-g / n$, which yields the indirect utility function:

\footnotetext{
${ }^{4}$ In addition, income is exogenous, inelastic to the tax rate, and unaffected by the consumption of either type of goods. This situation may apply, for instance, to a comparatively small province of a federal state, where the income of citizens depends on country-wide macroeconomic conditions and is not affected by the fiscal policy of the provincial government (which is constrained to run a balanced budget). In more general situations, the decisions concerning the allocation of resources between private and public consumption would have an impact on production, employment and income, and the effects of corruption should be analyzed in a model of general equilibrium.

${ }^{5}$ Different utility functions have been applied in the literature on spatial voting, depending on the type of problem being analyzed. For the purposes of this study, the quasilinear specification provides a good balance of tractability and generality.

${ }^{6}$ Most of the ensuing discussion can be simplified by normalizing $n$ to unity. That $n$ is larger than 1 becomes relevant when discussing the decision problem of an elected candidate (see Subsection III.A below).
} 


$$
V(g ; \theta) \equiv 1-\frac{g}{n}+\theta u(g) .
$$

$V(g ; \theta)$ measures the utility derived by a citizen of type $\theta$ when the amount of roads is equal to $g$ and the public and private budget constraints are binding. The value $g^{\theta}$ that maximizes this function, hereafter defined as the "ideal policy" of a citizen of type $\theta,{ }^{7}$ is identified by the first-order condition (FOC) $V_{g}^{\prime}(g ; \theta)=0$, equivalent to ${ }^{8}$

$$
u^{\prime}\left(g^{\theta}\right)=\frac{1}{n \theta}
$$

Since $g^{\theta}$ is strictly increasing in $\theta$, the ranking of citizens according to their ideal policy is the same as their ranking by type. Under the public budget constraint, the optimal tax rate for a citizen of type $\theta$ is equal to $t^{\theta}=g^{\theta} / n$.

Since the citizens have different policy preferences, the policy that is actually implemented (the amount of roads $g$ and the tax rate $t$ ) is chosen by the minister, who is in turn elected by the citizens among themselves in free elections in which each citizen casts one vote. In order to abstract from lobbying effects, we assume that the enterprises play no political role: competition and free entry drive any rents to zero so that the enterprises are indifferent between producing either type of goods or even going out of business. ${ }^{9}$ Enterprises only act as a conduit that enables the minister to effectively steal part of the funds that are allocated to the construction of roads - for instance, by paying bribes in exchange for overinvoicing (as in Johnson, 1975). ${ }^{10}$

Once elected, the minister implements the policy that maximizes his own personal utility, unconcerned about the impact of his decision on the utility of the other citizens, and unbound by any pre-electoral commitments. All citizens are aware of this and vote accordingly: voting for a candidate is equivalent to voting for the policy that maximizes his own utility once elected, which may differ not only from any policy announced before the elections but also from the policy that he would prefer as a nonelected citizen (this distinction becomes relevant

\footnotetext{
${ }^{7}$ In the literature on spatial voting, ideal policies are sometimes called “ideal points.”

${ }^{8}$ Since $V(g ; \theta)$ is concave in $g$, the ideal policy of each citizen is unique.

${ }^{9}$ This assumption becomes relevant when corruption is introduced, since corruption may induce the owners of the entreprises to support a larger road supply. In general, if the entrepreneurs have the right to vote, corruption alters the distribution of preferences. To the purposes of this study, this effect can be ignored.

10 This assumption allows to put in evidence the specific aspects related to the minister's incentives to expand public expenditure. In real life, the lobbying activity of special-interest groups interacts with the factors analyzed here and affects the equilibrium outcome.
} 
in the presence of corruption). ${ }^{11}$ All citizens can stand as candidates, and the election is won by the citizen/candidate who survives a hypothetical infinite sequence of pairwise contests. ${ }^{12}$ The outcome of this model is identified by the type of candidate that is elected minister and by the policy that that candidate implements once elected. An equilibrium of the model is an outcome such that (i) the elected minister cannot be defeated in a pairwise contest by any other candidate; (ii) the elected minister cannot increase his utility by implementing a different policy or changing his decision about corruption (accepting/rejecting the bribe); and (iii) if the elected minister has credibly committed before the election to accept or reject the bribe, he cannot improve his utility by reneging on this commitment. In equilibrium, the citizen/candidate that is elected is therefore a citizen whose ideal policy (once elected) is preferred by a majority to the ideal policy of any other citizen (Condorcet winner). In the absence of corruption, the only Condorcet winner is the median voter, ${ }^{13}$ whose type $\mu$ lies at the median of the distribution. ${ }^{14}$ In the absence of corruption, the median voter is elected and sets $g=g^{\mu}$ and $t=g^{\mu} / n$.

\section{A. How ministers respond to corruption: honest and corrupt citizens}

How does this outcome change in the presence of corruption? Corruption alters the policy choice of the elected minister, who spends more on road construction than he would otherwise since by doing so he can get more bribes. Aware of this fact, the citizens respond by electing a different candidate, who could be either a citizen motivated to act honestly, or a

\footnotetext{
${ }^{11}$ Similar assumptions are found in the "citizen-candidate" models of political equilibrium (for instance, Osborne and Slivinski, 1996; Besley and Coate, 1997). In our model, however, citizens do not have to register, and do not incur costs, to stand as a candidate; each citizen can vote for any citizen, including himself, who is thus a candidate "by default."

12 This simplifying assumption approximates the equilibrium outcome that occurs, under some circumstances, with various electoral systems. With plurality voting, for instance, when the costs of standing as a candidate are sufficiently low, equilibria with a single candidate or with candidates having the same policy preferences are equivalent to the equilibrium outcome that would result in an infinite sequence of pairwise contests (Osborne and Slivinski, 1996). With majority voting, a representative assembly reflecting the policy composition of its electorate would tend, on average, to elect a government whose policy preferences are equivalent to those of a single candidate that survives infinite pairwise contests. The equilibrium outcome of particular electoral systems may of course be different, but its analysis exudes from the scope of this paper.
}

${ }^{13}$ Although the singular is used to simplify the narrative in the rest of this paper, in general there may be more than one "median voter" (all with the same preferences). In such cases, the identity of the winner among the set of median voters will be decided by extrapolitical criteria such as random extraction, seniority, or educational qualifications. These aspects are not relevant for the present discussion.

${ }^{14}$ When the policy choice is unidimensional and preferences are single-peaked (as occurs as a result of the concavity of the indirect utility function $V(g ; \theta)$ ), the median voter is pivotal. The only Condorcet winners are therefore candidates who implement his ideal policy. Since each candidate, once elected, implements his own ideal policy, the Condorcet winner in the absence of corruption can only be the median voter himself. With corruption, as discussed below, the ideal policy of the elected candidate differs from that of a nonelected citizen of the same type, and the median voter ceases to be the Condorcet winner. 
corrupt citizen who is less inclined to spend on roads. This subsection discusses the impact of corruption on the policy choice of the minister. The citizens' response is discussed in the next two subsections.

What is meant by “corruption?” Corruption takes many forms. In this model, corruption is defined as the acceptance, by the minister, of a bribe from the enterprises that build the roads, for example, in exchange for paying them an inflated price (out of the government budget). There are several real-life examples of this type of corruption; a typical case is the manipulation of public procurement auctions. ${ }^{15}$ This type of corruption effectively enables the minister to steal part of the taxes paid by the citizens, and distorts the relative price of consumer goods and roads, altering the allocation of resources.

The minister raises the price paid by the government for each mile of roads from 1 to $p>1$, which exceeds production costs ( $p$ is assumed to be exogenous: for instance, it could be the maximum price that can be paid to contractors without triggering a serious investigation). In exchange, the enterprises that are selected as government suppliers pay the minister a bribe of amount $b$ for each mile of roads. This agreement is, of course, illegal and involves a positive risk of punishment. Free entry and competition among enterprises bidding for public contracts push the value of the bribe up to the artificial increase in the price of road granted by the minister: $b=p-1$ : the minister extracts all the rent from corruption. ${ }^{16}$ The minister, however, retains only a fraction $a<1$ of the bribe; the rest $(1-a)$ is spent on legal fees and other deadweight costs aimed at reducing the risk of punishment. ${ }^{17}$ The total amount of illegal gains perceived by the minister is thus equal to $a b g$, equivalent to a fraction $a$ of the bribe $b$ raised on $g$ miles of roads. The associated expected value of punishment, measured in units of the consumer good, if fixed and equal to $\pi$. We assume that the enterprises run no risk of punishment. ${ }^{18}$ The minister's net expected gains from corruption are thus equal to

\footnotetext{
${ }^{15}$ See for instance Rose-Ackerman (1975) and Beenstock (1979).

${ }^{16}$ This assumption ensures that the enterprises are not acting as an interest group to alter the allocation of resources in a particular direction. This assumption allows us to focus on how corruption alters the electoral choice of the voters. Some studies (Basu et al., 1992; Besley and McLaren, 1993; Mookherjee and Png, 1995) assume that the rent is shared between the agents that pay and receive the bribe according to the Nash bargaining solution.

${ }^{17}$ In alternative, one could assume that a fraction $1-a$ of the price increase is retained by the enterprises so that the minister only receives a bribe of amount $a b$ for each mile of roads (as in a Nash bargaining model). As mentioned above, however, this would give the enterprises a stake in corruption, making them a potentially influential interest group.

18 This assumption simplifies the analysis by making the value of the bribe independent from the risk of detection. In alternative, one could assume that the enterprise also runs a positive risk of punishment $\pi^{\prime}$, in which case the value of the bribe determined below would be equal to $p-1-\pi$ '.
} 
$a b g-\pi,{ }^{19}$ which he entirely spends on consumer goods. ${ }^{20}$ The minister pays taxes like any other citizen on his legal income but does not pay taxes on the bribes.

When corruption occurs, total public expenditure becomes equal to $p g=(1+b) g$, and the amount of taxes paid by each citizen becomes $(1+b) g / n$. Hence, the indirect utility function of a nonelected citizen-taxpayer becomes $V^{C}(g, b ; \theta) \equiv 1-(1+b) g / n+\theta u(g)=V(g ; \theta)-b g / n$, which is maximized by the policy $\hat{g}^{\theta}$ that solves $u^{\prime}\left(\hat{g}^{\theta}\right)=(1+b) g /(n \theta)=p g /(n \theta)$. The indirect utility function of the minister is somewhat different, as it includes the net illegal gains from corruption, $a b g-\pi$ :

$$
\tilde{V}^{C}(g, b, \pi ; \theta) \equiv V^{C}(g, b ; \theta)+a b g-\pi=1-\frac{(1+b-n a b) g}{n}+\theta u(g)-\pi,
$$

which is maximized by the policy $\tilde{g}^{\theta}$ that satisfies the FOC $u^{\prime}\left(\tilde{g}^{\theta}\right)=p^{*} /(n \theta)$, where $p^{*}=1+b-n a b<1$ is the effective tax rate that a corrupt minister pays for each unit of roads. Note that $\hat{g}^{\theta}$ and $\tilde{g}^{\theta}$, like $g^{\theta}$, are increasing in $\theta$. Moreover, $\hat{g}^{\theta}<g^{\theta}<\tilde{g}^{\theta}$ for each type $\theta$ : corruption alters the policy preferences of elected and nonelected citizens in opposite directions: non-elected citizens demand less roads (that become more costly for the taxpayer), whereas elected citizens engaging in corruption demand more roads (to collect more bribes). ${ }^{21}$

The fact that bribes are offered does not imply that the minister accepts them. Aside from any moral restraints, an elected citizen could decide to act honestly out of merely economic considerations: corruption entails a risk of punishment, and a minister engages in it only if the maximum expected utility that can be obtained by engaging in corruption exceeds the maximum utility that can be earned by being honest. If the minister accepts the bribe, he maximizes his utility by setting $g$ equal to $\tilde{g}^{\theta}$, which yields $\tilde{V}^{C}\left(\tilde{g}^{\theta}, b, \pi ; \theta\right)$. If the minister remains honest, he sets $g=g^{\theta}$ and obtains $V\left(g^{\theta} ; \theta\right)$. An elected citizen unrestrained by moral constraints thus engages in corruption if and only if $\tilde{V}^{C}\left(\tilde{g}^{\theta}, b, \pi ; \theta\right)>V\left(g^{\theta} ; \theta\right)$, which yields the following lemma (Figure 1):

\footnotetext{
${ }^{19}$ A necessary condition for corruption to be profitable for the minister is that $a>1 / n$, which assures that the gross gains from corruption, $a b g$, are larger than the additional tax burden arising from an inflated price of the public good, $b g / n$. This condition is easily satisfied for sufficiently large values of $n$. This seems to suggest that corruption should ceteris paribus be less frequent in small countries and that, when it occurs, it would involve larger bribes. However, the minister in a large country may also be able to retain a smaller share of the rent. Note that this condition would not be satisfied with $n=1$; the requirement $n>1$ has thus become relevant.

${ }^{20} \pi$ could also measure the amount of consumer goods spent by the minister ex ante to purchase insurance against the risk of punishment.

${ }^{21}$ Note, too, that $V^{C}(g, b ; \theta)<V(g ; \theta)$ for all $\theta$ and for all values of $g$ : other things being equal. Nonelected citizens suffer from the presence of corruption because they pay more taxes for equal amounts of roads. As discussed below, however, in equilibrium “other things" are not equal: the citizens vote for a different candidate that sets a lower value of $g$.
} 
Lemma: An elected citizen engages in corruption if and only if

$$
\Psi(\theta) \equiv \frac{g^{\theta}-p^{*} \tilde{g}^{\theta}}{n}+\theta\left[u\left(\tilde{g}^{\theta}\right)-u\left(g^{\theta}\right)\right]>\pi .^{22}
$$

Figure 1. The Minister's Expected Utility With and Without Corruption

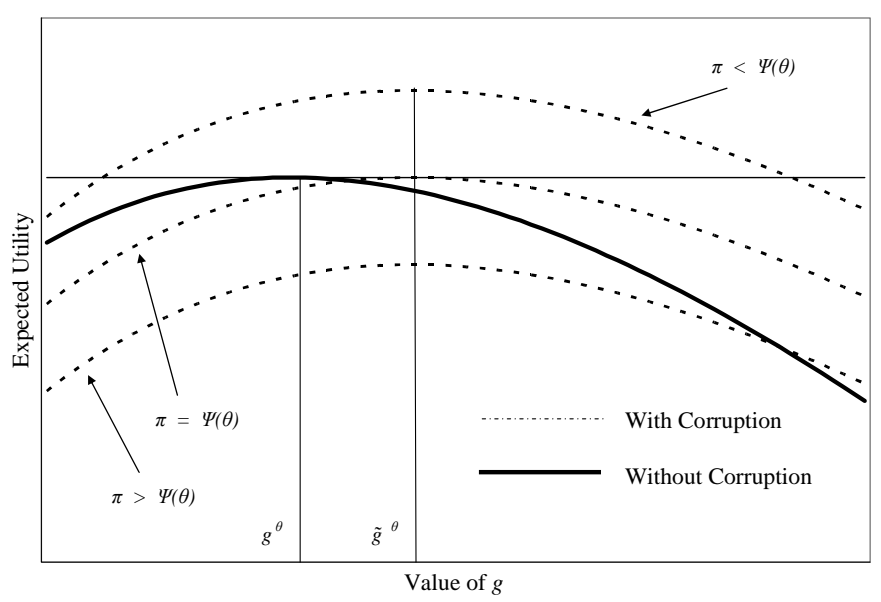

Hereafter, a citizen who, if he is elected minister, engages in corruption will be called "corrupt," while a citizen who acts honestly even once elected will be called "honest." This definition has no reference to a citizen's moral standards but merely describes the outcome of a rational, self-interested choice. All citizens in this model are assumed to be corruptible and unrestrained by moral considerations. From this lemma, whether a citizen is honest or corrupt only depends on his type $\theta$ and on the expected value of punishment. For any given value of $\pi$, the set of citizens can thus be partitioned into two subsets according to their type: a set $H(\pi)$ grouping all citizens for whom $\Psi(\theta)<\pi$, and a set $C(\pi)$ including all citizens for whom $\Psi(\theta)>\pi$. Citizens for whom $\Psi(\theta)=\pi$ are indifferent between being honest and corrupt; we assume that in this case they can publicly commit to either type of conduct before the election, once the value of $\pi$ is known. This commitment is credible since, once elected, the citizens do not have any incentive to deviate.

\footnotetext{
${ }^{22}$ Notice that $\Psi(\theta)>0$ : by definition of $\tilde{g}^{\theta}, \tilde{V}^{C}\left(\tilde{g}^{\theta}, b, 0 ; \theta\right)>\tilde{V}^{C}\left(g^{\theta}, b, 0 ; \theta\right)$. Moreover, since $a>1 / n$, then $\tilde{V}^{C}\left(g^{\theta}, b, 0 ; \theta\right)=V\left(g^{\theta} ; \theta\right)+b(n a-1) g^{\theta} / n>V\left(g^{\theta} ; \theta\right)$, hence $\tilde{V}^{C}\left(\tilde{g}^{\theta}, b, 0 ; \theta\right)>V\left(g^{\theta} ; \theta\right)$ and $\Psi(\theta)=\tilde{V}^{C}\left(\tilde{g}^{\theta}, b, 0 ; \theta\right)-$ $V\left(g^{\theta} ; \theta\right)>0$.
} 
Since $\Psi(\theta)$ is increasing in $\theta,{ }^{23}$ for a given value of $\pi$ the set $H(\pi)$ includes all citizens whose type lies below some threshold $\theta^{*}(\pi)=\Psi_{-}{ }^{1}(\pi)$, while the set $C(\pi)$ includes all citizens with $\theta$ $>\theta^{*}(\pi)$. Citizen whose type is equal to $\theta^{*}(\pi)$ are indifferent (Figure 2).

Figure 2. Honest and Corrupt Candidates by Type (Given $p$ )

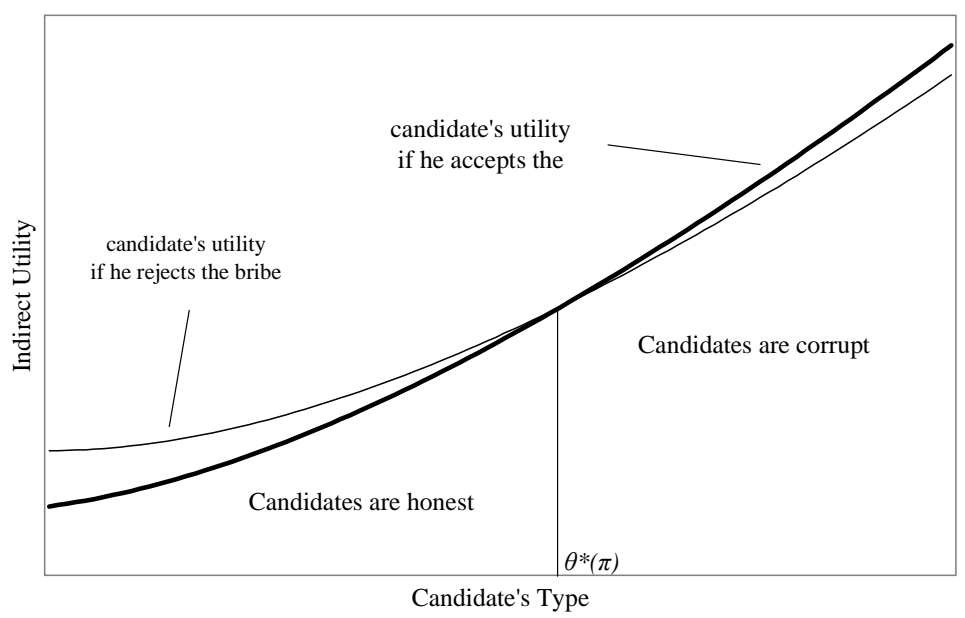

Both citizens' types and the expected value of punishment are common knowledge; therefore, at the time of the elections all citizens know who among them is honest or corrupt and vote accordingly. $^{24}$

${ }^{23}$ The first derivative of $\Psi(\theta)$ is equal to

$$
\begin{aligned}
& \Psi^{\prime}(\theta)=\frac{\frac{d g^{\theta}}{d \theta}-p^{*} \frac{d \tilde{g}^{\theta}}{d \theta}}{n}+\theta\left[u^{\prime}\left(\tilde{g}^{\theta}\right) \frac{d \tilde{g}^{\theta}}{d \theta}-u^{\prime}\left(g^{\theta}\right) \frac{d g^{\theta}}{d \theta}\right]+\left[u\left(\tilde{g}^{\theta}\right)-u\left(g^{\theta}\right)\right]= \\
& =\left[\frac{1}{n}-\theta u^{\prime}\left(g^{\theta}\right)\right] \frac{d g^{\theta}}{d \theta}-\left[\frac{p^{*}}{n}-\theta u^{\prime}\left(\tilde{g}^{\theta}\right)\right] \frac{d \tilde{g}^{\theta}}{d \theta}+\left[u\left(\tilde{g}^{\theta}\right)-u\left(g^{\theta}\right)\right]= \\
& =u\left(\tilde{g}^{\theta}\right)-u\left(g^{\theta}\right)>0
\end{aligned}
$$

since $\theta u^{\prime}\left(g^{\theta}\right)=1 / n$ and $\theta u^{\prime}\left(\tilde{g}^{\theta}\right)=p^{*} / n$, while $u\left(\tilde{g}^{\theta}\right)>u\left(g^{\theta}\right)$ since $\tilde{g}^{\theta}>g^{\theta}$.

\footnotetext{
${ }^{24}$ The fact that citizens are perfectly informed of which candidates are corrupt, and that, in spite of this, corruption is not always punished should not sound surprising. Citizens may be unable to prosecute their representatives even when they know that they are acting corruptly, for instance because the evidence available to the general public is not sufficient to secure a court conviction.
} 


\section{B. The political response of non-elected citizens}

How do nonelected citizens respond to corruption? In this sub-section, we discuss the citizens' choice when all candidates are corrupt (which occurs whenever the risk of punishment is sufficiently low, or equal to zero). ${ }^{25}$ The choice when some candidates are honest is discussed in the next subsection.

Proposition 1 When all candidates are corrupt, the citizens elect a candidate who ceteris paribus prefers a lower supply of roads than the majority of citizens; this candidate, once elected, chooses a larger supply of roads than preferred by a majority of citizens in the absence of corruption.

Proof: see Appendix.

Figure 3. Utility of a Nonelected Citizen as a Function of $\boldsymbol{g}$.

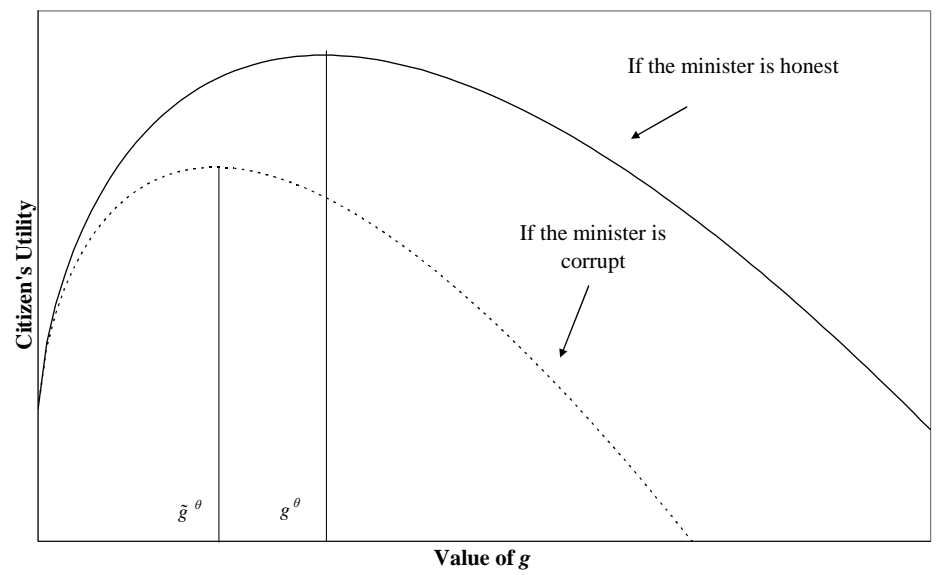

Note that the median voter would not elect a citizen of his own type, because, once elected, this citizen would not implement the policy preferred by a nonelected median voter $\left(\hat{g}^{\mu}\right)$, but a policy $\tilde{g}^{\mu}>\hat{g}^{\mu}$ that entails a larger supply of roads (Figure 4 ).

${ }^{25}$ All candidates are corrupt if and only if $\pi \leq \Psi(\underline{\theta})$, where $\underline{\theta}$ is the lowest citizen type $(\underline{\theta}=\min \{\theta: F(\theta)>0)$. 


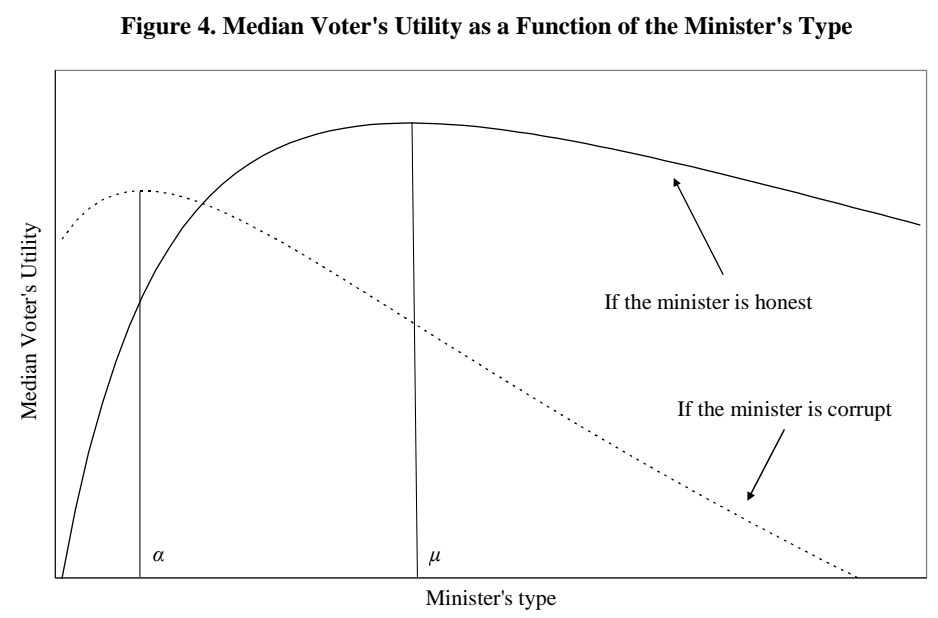

In summary: the citizens respond to the inflated cost of road construction by reducing their demand for roads. Since corruption induces elected candidates to expand road construction, the citizens elect a candidate who values roads less than the majority of citizens. If citizens' types are represented on a straight line running from right to left (with types on the left valuing roads more than types on the right) the citizens respond to a shift "to the left" of the policy preference of elected candidates by shifting their votes "to the right.", 26

The net effect on taxation depends on the demand elasticity of the median voter. Corruption yields lower taxes if and only if $(1+b) \hat{g}^{\mu}<g^{\mu}$, which is equivalent to the following condition, due to Allen and Lerner (1934):

Elasticity Condition (Allen and Lerner) The arc price elasticity of the demand for roads of the median voter is larger than unity:

$$
-\frac{\hat{g}^{\mu}-g^{\mu}}{b}\left(\frac{1+p}{g^{\mu}+\hat{g}^{\mu}}\right)>1 .^{27}
$$

When this condition holds, some citizens may indirectly benefit from corruption, because corruption brings the choice of the community in equilibrium closer to their own preferred policy:

\footnotetext{
${ }^{26}$ The words "right" and "left" are not used here in their usual political connotation but only to highlight the ordering of citizens' preferences by type. Left-wing political parties frequently exhibit a comparatively strong preference for public goods, and right-wing parties are more inclined to reduce taxes, but there are exceptions (the political right, for instance, might spend more than the left on national security, a particular example of public good).

${ }^{27}$ From $(1+b) \hat{g}^{\mu}=p \hat{g}^{\mu}<g^{\mu}$ follows $p\left(\hat{g}^{\mu}-g^{\mu}\right)<-b g^{\mu}$ and $b \hat{g}^{\mu}<g^{\mu}-\hat{g}^{\mu}$, whence $-b\left(g^{\mu}+\hat{g}^{\mu}\right)>(1+p)\left(\hat{g}^{\mu}-g^{\mu}\right)$, yielding (4).
} 
Proposition 2 When all candidates are corrupt and the Elasticity Condition holds, a minority of citizens may indirectly benefit from the shift in policy induced by corruption.

Proof: see Appendix.

\section{The choice between honest and corrupt candidates}

Assume now that the risk of punishment is sufficiently high to induce some citizens to be honest $(\pi>\Psi(\underline{\theta}))$. Under what conditions would one of them be elected?

Let us prove first of all that the median voter is pivotal in this choice. Consider the choice between two candidates of generic type $\theta_{1}$ and $\theta_{2}$. If both of them are either honest or corrupt, the citizens are confronted with a unidimensional policy choice under a single-peaked utility function, and the median voter is pivotal based on the median voter theorem. If, instead, one of the candidates (say, $\theta_{1}$ ) is honest and the other is corrupt, a generic citizen of type $\theta$ prefers the former to the latter if and only if $V\left(\theta_{1} ; \theta\right)>V^{C}\left(\theta_{2}, b ; \theta\right)$, which yields:

$$
\theta>\frac{g^{\theta_{1}}-(1+b) \tilde{g}^{\theta_{2}}}{n\left[u\left(g^{\theta_{1}}\right)-u\left(\tilde{g}^{\theta_{2}}\right)\right]} \text { or } \theta<\frac{g^{\theta_{1}}-(1+b) \tilde{g}^{\theta_{2}}}{n\left[u\left(g^{\theta_{1}}\right)-u\left(\tilde{g}^{\theta_{2}}\right)\right]}
$$

depending on whether or not $g^{\theta_{1}}>\tilde{g}^{\theta_{2}}$. Hence, any majority in the choice between the two candidates includes the median voter, who remains pivotal.

Obviously, if the median voter is honest $\left(\mu \leq \theta^{*}(\pi)\right)$, he is elected minister: by revealed preferences, a majority of citizens prefer him to any corrupt candidate. ${ }^{28}$ We therefore restrict the discussion to cases in which the median voter is corrupt $\left(\mu>\theta^{*}(\pi)\right)$. In this situation, the citizens have to trade off the benefits of electing an honest candidate for the disadvantage of electing a candidate that implements less preferred policies. In some cases, the citizens elect an honest candidate, even if his policy preferences are different from those preferred by the majority. In other cases, they elect a corrupt candidate that, once elected, implements the policy that most closely resembles the ideal policy of the median voter.

Proposition 3 When the median voter is corrupt, corruption alters the equilibrium policy outcome by inducing either the election of a corrupt candidate or the election of an honest candidate with policy preferences different from the median.

\footnotetext{
${ }^{28} \mathrm{~A}$ corrupt candidate of generic type $c \in C(\pi)$ would set $g=\tilde{g}^{c}$ and $t=(1+b) \tilde{g}^{c} / n$; this is strictly dominated, for all citizens, by the policy $g=\tilde{g}^{c}, t=\tilde{g}^{c} / n$, which would be achieved by electing a citizen of type $c^{\prime}=c / p^{*}$ if the latter were honest. To this policy, however, the median voter (and hence a majority) prefers the policy $g=\tilde{g}^{\mu}$ and $t=g^{\mu} / n$ that is achieved by electing the median voter, if the latter is honest. Hence, a fortiori, the median voter (and with him a majority) prefers this last policy to the policy implemented by any corrupt candidate.
} 
Proof: see Appendix.

When an honest citizen other than the median voter is elected, the alteration of the equilibrium induced by corruption always benefits a minority of citizens, because the price paid for each mile of roads does not change.

\section{VOTING ON LAW ENFORCEMENT}

Thus far, the expected value of punishment, $\pi$, has been treated as exogenous. In fact, this variable is are affected by a variety of institutional decisions concerning the accountability of public officials, the mandate and resources of law enforcement agencies, the power of the judiciary, the definition of crimes and the punishment that can be enforced, and the constitutional rights of individual citizens and public officials. These decisions, which we can indicate in aggregate as the "law enforcement regime," jointly determine the probability that an official guilty of corruption can be detected, successfully prosecuted, and punished, as well as the value of the punishment he would suffer in this case. ${ }^{29}$ In democracy, decisions concerning the reform of the law enforcement regime are ultimately made by the citizens.

The law enforcement regime cannot be changed rapidly (although some parts of it, such as the budget of the police, can) and its reforms produce their effects with a long time lag; it is therefore set (or reformed) taking a long-term view of its impact on the variables of interest. By affecting the incentives to engage in corruption, the law enforcement regime determines which candidates are honest or corrupt and thus has an indirect impact on the policy choice that is adopted in equilibrium. It is then conceivable that, when deciding on law enforcement, the citizens take this impact into account. In this sense, decisions on law enforcement are comparable to decisions on constitutional reform: just like constitutions, which "are not really made behind a Rawlsian veil of ignorance" (van Winden, 1999, p. 20), ${ }^{30}$ the law enforcement regime is chosen taking into consideration its impact on the subsequent political equilibrium. Citizens who stand to benefit (indirectly) from the impact of corruption on policy choice will tend to support institutional arrangements that are more favorable to corruption, emphasizing, for instance, the personal right to privacy, protection against intrusive investigations and disclosure of requirements, and defense in court; whereas citizens who stand to lose from corruption will vote in favor of giving more power and resources to the judiciary, police, and public prosecutors. Citizens who stand to suffer from corruption will also be less favorable to policies that create opportunities for illegal rentseeking, such as protectionism.

\footnotetext{
${ }^{29}$ In this paper, "law enforcement" only refers to the enforcement of rules prohibiting corruption. There is, of course, a large area of law enforcement that is not related to corruption, that is not discussed here.

${ }^{30}$ Similar considerations may apply more generally to all institutional decisions bearing long-term effects on future policy choices. The shift toward central bank independence has been explained, for instance, on the basis of long-term electoral interests of elected politicians (Bernhard, 2002; McGregor, 2007).
} 
In this model, the collective decisions on law enforcement are formalized as a onedimensional choice on a single parameter, the expected value of punishment $\pi$, that summarizes the effects of all decisions concerning the enforcement of laws against corruption.

The value of $\pi$ is decided at an initial "constitutional" stage of the game, when the citizens delegate this choice to an elected representative - the "constituent" - who decides only on the basis of his own personal preferences, with no possibility of a credible precommitment. ${ }^{31}$ The constituent only chooses the value of $\pi$; he cannot make decisions on taxes or public expenditure, which remain the prerogative of the minister that is elected at a subsequent "political" stage. The constituent cannot directly influence the election of the minister, but he can stand as a candidate in this election. The set of citizens (and hence the distribution of preferences) can vary between the constitutional and the political stage according to a probability distribution that is common knowledge: with probability $q$, the distribution of preferences does not change, while with probability $1-q$ new citizens enter the community at the political stage, shifting the median type toward "the left." Two "states of the world" are thus possible at the political stage: if the distribution of preferences is the same as in the constitutional stage, the state is "conservative," while if the distribution changes to the left the state is "progressive." ${ }^{32}$ A majority of citizens present at the constitutional stage will be called a "constitutional majority." Moreover, the citizen(s) whose type $v$ lies at the median of the distribution at the constitutional stage will be called the "constitutional median voter," (CMV) while the citizen(s) whose type $\mu$ lies at the median at the political stage will be called the "political median voter" (PMV). Hence, $\mu=v$ with probability $q$ and that $\mu=\xi>v$ with probability $1-q$.

Consider the policy expectations of the citizens at the constitutional stage. They know that, with probability $1-q$, the distribution of preferences at the political stage will shift in favor of a higher supply of roads. For most of them, the policy choice that is adopted in this case in the absence of corruption involves too many roads and excessive taxes. The citizens are aware, however, that corruption can alter this choice in favor of less roads and-if the Elasticity Condition holds-lower taxes. Under certain conditions, this outcome would be preferable for a constitutional majority, who can thus use the institutional environment as a tool to alter the political equilibrium in their favor. We assume here that that is the case. Formally, this implies that $V\left(g^{\xi} ; v\right)<V^{C}\left(\hat{g}^{\xi}, b ; v\right)$ : in the progressive state of the world, the CMV prefers the policy outcome that occurs when all candidates are corrupt (whereby a corrupt minister sets $g=\hat{g}^{\xi}$ ) to the outcome that occurs in the absence of corruption (when

\footnotetext{
${ }^{31}$ This is, of course, a simplified representation of the process. In most cases (the founding of a new country being a rare exception), the institutional environment is not set once and for all at a separate constitutional stage, but evolves through a gradual and ongoing process of institutional innovation and reform.

${ }^{32}$ We assume that the number of citizens is the same in both states: in the conservative state, , the preferences of the citizens that enter the community at the political stage are distributed like those of the citizens that are already present at the constitutional stage.
} 
the PMV is elected and sets $g=g^{\xi}$ ). This, of course, only happens if the Elasticity Condition holds in the progressive state.

In the ensuing discussion, we abstract from the costs of law enforcement. Normally, a more effective law enforcement regime (a higher value of $\pi$ ) involves higher costs that are borne by the citizens through taxes (for instance, recruiting more police officers raises the public wage bill). These costs are taken into account when choosing the appropriate level of law enforcement. Here, we assume that law enforcement is costless, to emphasize how corruption can arise for mere political reasons. The model can easily be generalized to include positive, increasing enforcement costs.

\section{A. Law enforcement and policy choice}

At the political stage, when $\pi$ has already been set, the citizens elect the minister among one of two sets of citizens: corrupt and honest. As shown in the previous section, the median voter (the PMV) is pivotal. We have also shown that the citizens do not always end up electing an honest candidate and that if, at the given value of $\pi$, all honest candidates have policy preferences too different from those of the PMV, the citizens elect a corrupt candidate who, as minister, implements a policy that is closer to the preferences of the PMV and hence of the majority.

To enhance tractability, we assume here that $u(g)$ is thrice differentiable with $u$ "' $(g) \leq 0$ for all $g$. The implications of this condition will become clear below (footnote 40 ), ${ }^{33}$ but the results can be generalized to a wider set of utility functions.

Note that (i) when $\pi \geq \pi^{\mu}$ the PMV is honest and is elected; (ii) when $\pi<\pi^{\mu}$, the PMV prefers, among all honest candidates, the candidate with the highest value of $\theta$ in $H(\pi)$, who is a

\footnotetext{
${ }^{33}$ The restriction $u$ "' $\leq 0$ ensures that the derivative of $\tilde{g}^{\theta}$ with respect to $\theta$ for a corrupt minister is larger than the derivative of $g^{\theta}$ with respect to $\theta$ for an honest minister of the same type. Let $p^{o} \in\left\{1, p^{*}\right\}$ be net the unit price of roads paid by the minister (which is equal to 1 if the minister is honest and to $p^{*}<1$ if he is corrupt); let $g^{o} \in\left\{g^{\theta}, \tilde{g}^{\theta}\right\}$ be the policy choice of the minister (equal to $g^{\theta}$ if he is honest and to $\tilde{g}^{\theta}$ if he is corrupt). The FOC for maximization requires that $u^{\prime}\left(g^{o}\right)=p^{o} /(n \theta)$; differentiating with respect to $g$ and to $\theta$ yields $u^{\prime \prime}\left(g^{o}\right) d g^{o}=$ - $p^{o} /\left(n \theta^{2}\right) d \theta=-u^{\prime}\left(g^{o}\right) / \theta d \theta$, whence $d g^{o} / d \theta=-u^{\prime}\left(g^{o}\right) /\left(u^{\prime \prime}\left(g^{o}\right) \theta\right)$. Differentiating $d g^{o} / d \theta$ with respect to $p^{o}$ yields:

$$
\begin{aligned}
& \frac{d^{2} g^{o}}{d \theta d p^{o}}=-\left(\frac{\left[u^{\prime \prime}\left(g^{o}\right)\right]^{2} \theta-u^{\prime}\left(g^{o}\right) u^{\prime \prime \prime}\left(g^{o}\right) \theta}{\left[u^{\prime \prime}\left(g^{o}\right) \theta\right]^{2}}\right) \frac{d g^{o}}{d p^{o}}= \\
& =-\frac{1}{\theta}\left(1-\frac{u^{\prime}\left(g^{o}\right) u^{\prime \prime \prime}\left(g^{o}\right)}{\left[u^{\prime \prime}\left(g^{o}\right)\right]^{2}}\right) \frac{d g^{o}}{d p^{o}} .
\end{aligned}
$$
}

Since $d g^{\circ} / d p^{o}<0$ for $p^{o}>1$, a sufficient condition for this derivative to be positive in the interval $\left(1, p^{*}\right)$ is that $u^{\prime \prime \prime}(g) \leq 0$ for all $g$. When this occurs, $d g^{\circ} / d \theta$ is larger when the minister is honest $\left(p^{o}=1\right)$ than when he is corrupt $\left(p^{o}=p^{*}<1\right)$. 
candidate of type $\theta^{*}(\pi)$ that has (credibly) signaled his intention to remain honest once elected; (iii) when $\pi$ is below some threshold $\pi^{A} \equiv \Psi(\alpha)$, candidates of type $\alpha=\left(p^{*} / p\right) \mu$ are corrupt and the PMV prefers them to any other candidate in $C(\pi)^{34}$; (iv) when $\pi>\pi^{A}$ citizens of type $\alpha$ are honest and the PMV prefers, among all corrupt candidates, those with the lowest value of $\theta$, who are citizens of type $\theta^{*}(\pi)$ that have failed to manifest their intention to act honestly (and are thus correctly deemed to be corrupt).

Hence,

(i) when $\pi \geq \pi^{A}$, the PMV prefers an honest candidate of type $\theta^{*}(\pi)$ to all other honest candidates and a corrupt candidate of the same type $\theta^{*}(\pi)$ to all other corrupt candidates. The citizens elect a minister of type $\gamma \equiv \theta^{*}(\pi)$, who is honest or corrupt depending on whether the utility of the nonelected PMV is higher if he acts honestly or corruptly-formally, whether or not $V\left(\theta^{*}(\pi) ; \mu\right)>V^{C}\left(\theta^{*}(\pi), b ; \mu\right)$, which is equivalent to

$$
\mu\left[u\left(g^{\gamma}\right)-u\left(\tilde{g}^{\gamma}\right)\right]-\frac{g^{\gamma}-p \tilde{g}^{\gamma}}{n}>0,
$$

where $g^{\gamma}$ and $\tilde{g}^{\gamma}$ are both functions of $\theta^{*}(\pi)$, and hence of $\mu$ and $\pi$. The LHS of (6) is increasing in $\theta^{*}(\pi),{ }^{35}$ hence in $\pi$, which implies that a majority prefers the honest candidate if $\pi$ lies above some value $\pi^{B}<\pi^{\mu} .{ }^{36}$ Since the LHS is also increasing in $\mu$, $\pi^{B}$ is a decreasing function of $\mu$, implying that $\pi^{B}(v)>\pi^{B}(\xi)$.

(ii) if $\pi<\pi^{A}$, the PMV still prefers an honest candidate of type $\theta^{*}(\pi)$ to all other honest candidates, but his preferred corrupt candidate is now a citizen of type $\alpha$. The citizens elect the honest candidate of type $\theta^{*}(\pi)$ if and only if $V\left(\theta^{*}(\pi) ; \mu\right)>V^{C}(\alpha, b ; \mu)$, which is equivalent to

${ }^{34}$ See the proof of Proposition 1 in Appendix.

${ }^{35}$ The first derivative of the LHS of (7) with respect to $\gamma \equiv \theta^{*}(\pi)$ is equal to:

$$
\begin{aligned}
& \mu\left[u^{\prime}\left(g^{\gamma}\right) \frac{d g^{\gamma}}{d \gamma}-u^{\prime}\left(\tilde{g}^{\gamma}\right) \frac{d \tilde{g}^{\gamma}}{d \gamma}\right]-\frac{\frac{d g^{\gamma}}{d \gamma}-p \frac{d \tilde{g}^{\gamma}}{d \gamma}}{n}= \\
& =\frac{1}{n}\left\{\left(\frac{\mu}{\gamma}-1\right) u^{\prime}\left(g^{\gamma}\right) \frac{d g^{\gamma}}{d \gamma}-\left(\frac{\mu}{\gamma}-\frac{p}{p^{*}}\right) u^{\prime}\left(\tilde{g}^{\gamma}\right) \frac{d \tilde{g}^{\gamma}}{d \gamma}\right\} .
\end{aligned}
$$

Since $p>p^{*}$, given that $u^{\prime}\left(g^{\gamma}\right)>u^{\prime}\left(\tilde{g}^{\gamma}\right)$, a sufficient condition for the first derivative to be positive is that $d g^{\gamma} / d \theta$ $>d \tilde{g}^{\gamma / d} \theta$, which is assured by the restriction $u{ }^{\prime \prime}(g) \leq 0$.

${ }^{36}$ Since the political median voter is always elected when he is honest, the hypothetical case in which $\pi^{B}>\pi^{\mu}$ is irrelevant. Given that the political median voter always prefers an honest citizen of his type to a corrupt citizen of his type, then $\pi^{A}<\pi^{\mu}$ implies $\pi^{B}<\pi^{\mu}$. 


$$
\mu\left[u\left(g^{\gamma}\right)-u\left(\tilde{g}^{\alpha}\right)\right]-\frac{g^{\gamma}-p \tilde{g}^{\alpha}}{n}>0 ;
$$

otherwise, they elect a corrupt citizen of type $\alpha$. Since the LHS is increasing in $\theta^{*}(\pi)$ (hence in $\pi$ ) for $\theta^{*}(\pi)<\mu^{37}$, this inequality holds only if $\pi$ lies above some threshold $\pi^{C}>\pi^{B}$.

Note that, while $\theta^{*}(\pi)$ does not depend on $\mu$ but only on $\pi$, the values of $\alpha, \pi^{A}, \pi^{B}$ and $\pi^{C}$ change with $\mu$ and will be hereafter indicated when appropriate as functions of $\mu$. It is easily seen that $\pi^{A}(v)<\pi^{A}(\xi)$, since $\alpha(v)<\alpha(\xi)$, and that $\pi^{B}(v)<\pi^{B}(\xi)$ (the LHS of (6) is increasing in both $\pi$ and $\mu$ ). If, in addition, $\pi^{A}<\pi^{B}<\pi^{C}$ both when $\mu=v$ and when $\mu=\zeta>v$, ${ }^{38}$ in each state of the world four different law enforcement regimes are possible (Figure 5):

- $\quad$ Permissive: $\pi \leq \pi^{A}(\mu)$. Corruption is effectively permitted. Law enforcement is too weak not only to prevent corruption but also to contain its distortion of the policy choice. The citizens elect a corrupt candidate of type $\alpha(\mu)$, who sets $g=\tilde{g}^{\alpha(\mu)}$ and $t=$ $(1+b) \tilde{g}^{\alpha(\mu)} / n$. An extreme case of permissive regime- “full permission”-occurs when $\pi=0$ and corruption is nominally forbidden but effectively unpunished.

- $\quad$ Tolerant: $\pi^{A}(\mu)<\pi<\pi^{B}(\mu)$. Corruption is tolerated; the enforcement of anticorruption laws has an observable impact on policy outcomes, but corruption still occurs in equilibrium. The citizens elect a corrupt candidate of type $\theta^{*}(\pi)$, who sets $g=\tilde{g}^{\gamma}$ and $t=(1+b) \tilde{g}^{\gamma / n}$. Note that the utility of the PMV and of a majority of the citizens at the political stage is lower under a tolerant regime than under a permissive one.

- $\quad$ Strong: $\pi^{B}(\mu) \leq \pi<\pi^{\mu}$. Corruption is repressed but lingers under the surface. It does not occur in equilibrium, but its threat has an impact on policies by reducing the set of honest candidates. The citizens elect an honest candidate of type $\theta^{*}(\pi)$, who sets $g=g^{\gamma}$ and $t=g^{\gamma} / n$.

${ }^{37}$ The first derivative with respect to $\theta^{C}(\pi)$ is equal to

$$
\left(\mu u^{\prime}\left(g^{\gamma}\right)-\frac{1}{n}\right) \frac{d g^{\gamma}}{d \gamma}=\frac{1}{n}\left(\frac{\mu}{\gamma}-1\right) \frac{d g^{\gamma}}{d \gamma},
$$

which is positive when $\gamma \equiv \theta^{*}(\pi)<\mu$.

${ }^{38} \pi^{C}$ is always larger than $\pi^{B}$ because, when $\pi>\pi^{C}$, the PMV prefers an honest candidate of type $\theta^{*}(\pi)$ to a corrupt candidate of type $\alpha$ while, when $\pi<\pi^{B}$, he prefers a corrupt candidate of type $\theta^{*}(\pi)$ to an honest candidate of the same type. Since, by definition, the PMV prefers a corrupt candidate of type $\alpha$ to a corrupt candidate of any other type, $\pi^{B}$ cannot be larger than $\pi^{C}$. The case in which $\pi^{A}>\pi^{C}>\pi^{B}$ is less interesting: the PMV prefers either an honest candidate of type $\theta^{*}(\pi)$ (if $\pi>\pi^{C}$ ) or a corrupt candidate of type $\alpha$ (if $\pi<\pi^{C}$ ). As discussed below, in this case, $\pi$ is set either equal to $\pi^{v}$ or to zero. 
- $\quad$ Effective: $\pi \geq \pi^{\mu}$. Corruption is completely prevented. Law enforcement is sufficiently strong to induce the PMV to be honest; the latter is therefore elected, and sets $g=g^{\mu}$ and $t=g^{\mu} / n$.

Figure 5. Median Voter's Utility as a Function of $\pi$

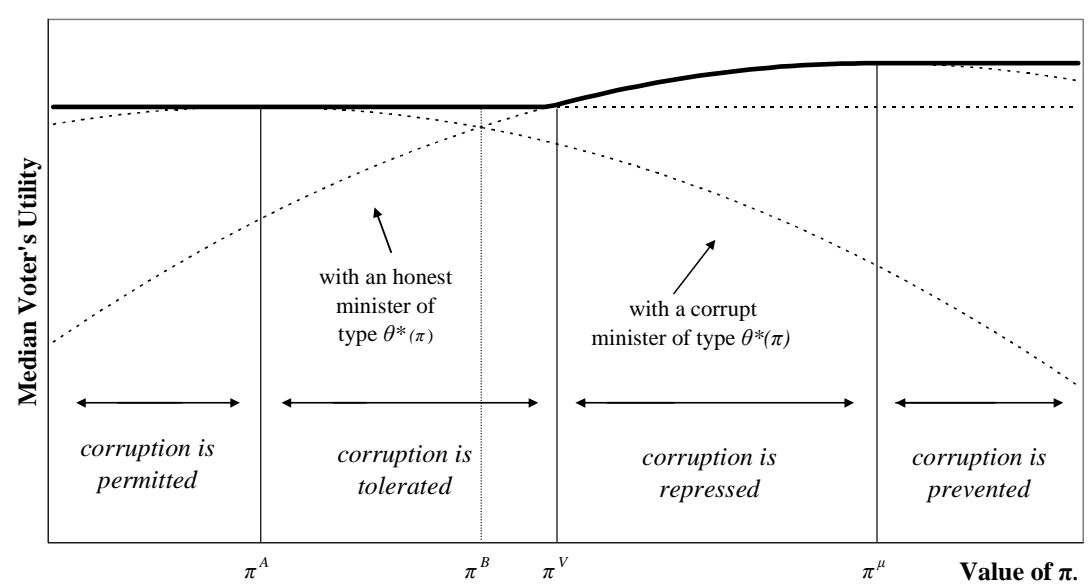

The citizens elect a corrupt candidate only under a permissive or tolerant regime (when $\pi<$ $\pi^{B}$ ). Since $\pi^{B}(v)<\pi^{B}(\xi)$, when $\pi<\pi^{B}(v)$, the citizens elect a corrupt candidate in both states of the world. If $\pi$ is larger than $\pi^{A}(\xi)$, in both states of the world the citizens elect a corrupt candidate of type $\theta^{*}(\pi)$. Otherwise, the citizens elect candidates of different types depending on the state of the world. When $\pi^{B}(v)<\pi<\pi^{B}(\xi)$, the citizens elect an honest candidate of type $\theta^{*}(\pi)$ in the conservative state ${ }^{39}$ and a corrupt candidate (of the same type) in the progressive state. When $\pi>\pi^{B}(\xi)$, the citizens elect an honest candidate in both states of the world, which is of the same type $\theta^{*}(\pi)$ if $\pi<\pi^{v}$, and of different types otherwise.

\section{B. Deciding on law enforcement}

This relation between the value of $\pi$ and the candidate that is elected (hence, the policy that is adopted) in equilibrium is taken into account by the citizens at the constitutional stage of the game. Note that setting $\pi$ at any level $0 \leq \pi<\pi^{A}(v)$ always results in the election of a corrupt candidate of type $\alpha(\mu)$; in the same way, setting $\pi$ at any level $\pi \geq \pi^{\xi}$ induces the election of the (honest) PMV. In these cases, we assume that the citizens at the constitutional stage will choose the lowest level of $\pi$ within these intervals ( 0 and $\pi^{\xi}$ respectively), as would occur if the costs of law enforcement increased even modestly in $\pi$.

Let $z(\pi, \mu)$ be the type of the candidate that is elected, at the political stage, under a given legal regime (identified by $\pi$ ) and a given state of the world (identified by $\mu$ ). Let $l(\pi, \mu)$ be an

${ }^{39}$ Unless $\pi^{v}<\pi<\pi^{B}(\xi)$, in which case, in the conservative state, they elect the PMV. 
indicator equal to 1 if $z$ is honest (which depends, of course, on $\pi$ and on $\mu$ as discussed above) and to 0 otherwise. Let $\imath^{*}=1-\imath$, and let $W(\pi, \mu ; \theta)$ be the indirect utility that a citizen derives when $z(\pi, \mu)$ is elected (whether honest or corrupt depending on $\imath(\pi, \mu)$ ) and implements his own preferred policy. $W(\pi, \mu ; \theta)$ is equal to

$$
\begin{aligned}
& \imath\left(\theta u\left(g^{z}\right)-\frac{g^{z}}{n}\right)+\imath^{*}\left(\theta u\left(\tilde{g}^{z}\right)-\frac{p \tilde{g}^{z}}{n}\right)=\theta\left(\imath u\left(g^{z}\right)+\imath^{*} u\left(\tilde{g}^{z}\right)\right)-\frac{\imath g^{z}+\imath^{*} p \tilde{g}^{z}}{n}= \\
& =\theta \Psi(\pi, \mu)+\Xi(\pi, \mu),
\end{aligned}
$$

where $\Psi(\pi, \mu)=\imath u\left(g^{z}\right)+\imath^{*} u\left(\tilde{g}^{z}\right)$ and $\Xi(\pi, \mu)=-\left(l g^{z}+\imath^{*} p \tilde{g}^{z}\right) / n$ depend on $\imath, g^{z}$ and $\tilde{g}^{z}$, hence on $\pi$ and $\mu$. The function $W(\pi, \mu ; \theta)$ is common knowledge.

Since the value of $\mu$ at the political stage is a random variable at the constitutional stage, the expected value of the indirect utility that a citizen of type $\theta$ derives for a given value of $\pi$ before the realization of $\mu$ is known is equal to $W^{E}(\pi, q ; \theta) \equiv q W(\pi, v ; \theta)+(1-q) W(\pi, \xi ; \theta)=$ $\theta \Psi^{*}(q, \pi)+\Xi^{*}(q, \pi)$, where $\Psi^{*}(q, \pi)=q \Psi(\pi, v)+(1-q) \Psi(\pi, \xi)$ and $\Xi^{*}(q, \pi)=q \Xi(\pi, v)+$ $(1-q) \Xi(\pi, \xi)$.

The choice of $\pi$ is delegated to the constituent elected at the constitutional stage, who sets it at the level that maximizes his own expected utility. It is easy to see that the CMV is pivotal at this stage: in a pairwise choice between two values of $\pi$ (say, $\pi_{1}$ and $\pi_{2}$ ), the CMV always votes with the majority. ${ }^{40}$ Therefore, the constitutional stage of the game has a unique equilibrium in which the CMV is elected as constituent and sets $\pi$ at the level that maximizes $W^{E}(\pi, q ; v)$.

The characteristics of this equilibrium depend on the relative values of some key parameters of the model, including $\pi^{B}(\xi), \pi^{v}$ and $\pi^{\xi}$ as well as $\left.W\left(\pi^{B}(\xi)\right), \xi ; v\right)$ and $W\left(\pi^{A}(\xi), \xi ; v\right)$. Hereafter, we discuss the case in which $\pi^{B}(\xi)<\pi^{v}$ and the case in which $\pi^{B}(\xi)>\pi^{v}$ and $\left.W\left(\pi^{B}(\xi)\right), \xi ; v\right)<$ $W\left(\pi^{A}(\xi), \xi ; v\right)$. The case in which $\pi^{B}(\xi)>\pi^{v}$ but $\left.W\left(\pi^{B}(\xi)\right), \xi ; v\right) \geq W\left(\pi^{A}(\xi), \xi ; v\right)$ will not be discussed because it yields a qualitatively similar outcome to the case in which $\pi^{B}(\xi)<\pi^{v}{ }^{41}$

When $\pi^{B}(\xi)<\pi^{v}$, corruption is always prevented in equilibrium in both states of the world:

\footnotetext{
${ }^{40}$ Given the value of $q$, without loss of generality, let us order the two alternatives such that $\Psi^{*}\left(\pi_{1}, q\right)>\Psi^{*}\left(\pi_{2}, q\right)$. A citizen at the constitutional stage prefers $\pi_{1}$ to $\pi_{2}$ if and only if $W^{E}\left(\pi_{1}, q ; \theta\right)>W^{E}\left(\pi_{2}, q ; \theta\right)$, which yields: $\theta>$ $\theta^{* *}\left(\pi_{1}, \pi_{2}\right) \equiv\left[\Xi^{*}\left(\pi_{2}, q\right)-\Xi^{*}\left(\pi_{1}, q\right)\right] /\left[\Psi^{*}\left(\pi_{1}, q\right)-\Psi^{*}\left(\pi_{2}, q\right)\right]$. Hence, the majority always includes the CMV.

${ }^{41}$ When $\pi^{B}(\xi)>\pi^{v}$ but $\left.W\left(\pi^{B}(\xi)\right), \xi ; v\right) \geq W\left(\pi^{A}(\xi), \xi ; v\right)$, the CMV prefers to prevent corruption in both states, setting $\pi=\pi^{B}(\xi)>\pi^{v}$. The outcome is qualitatively similar to the case discussed in Proposition 4, with the difference that in the progressive state the citizens elect a minister that constructs more roads than preferred by the CMV and less roads than preferred by the PMV.
} 
Proposition 4 When $\pi^{B}(\xi)<\pi^{v}$, corruption does not occur in any state of the world. In the conservative state it is completely prevented, while in the progressive state it is repressed and alters the equilibrium policy choice in a direction favorable to the constitutional majority.

Proof: see Appendix.

In other words, the constitutional majority implements an enforcement regime which is sufficiently strong to prevent any policy distortions in the conservative state and to prevent corruption in the progressive state, but it is also sufficiently weak to induce the election of the CMV instead of the PMV in the progressive state. This is obtained by ensuring that all other candidates that would be preferred to the CMV by a majority in the progressive state would be corrupt.

This outcome is certainly preferred by a constitutional majority to all other possible outcomes but is not always feasible. If $\pi^{B}(\xi)>\pi^{v}$ and $\left.W\left(\pi^{B}(\xi)\right), \xi ; v\right)<W\left(\pi^{v}, \xi ; v\right)$ in particular, the CMV's expected utility can only be maximized by allowing corruption to occur in the progressive state, which of course would leave him worse off.

Proposition 5 When $\pi^{B}(\xi)>\pi^{v}$ and $\left.W\left(\pi^{B}(\xi)\right), \xi ; v\right)<W\left(\pi^{v}, \xi ; v\right)$, corruption always occurs in the progressive state. For sufficiently large (in some cases for all) values of q, it is prevented in the conservative state, whereas for smaller values of $\mathrm{q}$ and under certain conditions, it is fully permitted in both states.

Proof: see Appendix.

\section{Conclusions}

This paper examined whether corruption can persist in a well-functioning democracy in which citizens make rational and fully informed decisions. We found that, under certain conditions, this is at least theoretically possible. Corruption distorts the allocation of resources between public and private uses, and if the citizens expect future changes in preferences concerning this allocation, they can use corruption to alter the future collective choice in their favor. Hence, corruption does not necessarily stem from a failure of the democratic system, although it ends up causing one (by limiting the choices available to the citizens in the future). Corruption thus has an important political dimension that must be taken into account in the design of anticorruption strategies.

The paper also highlighted other features of the political economy of corruption in democracy. Somewhat counterintuitively, corruption tends to reduce public expenditure when measured in real (physical) terms, as the citizens respond to corruption by reducing demand for goods (public goods, in our model) whose price is inflated by bribery. If this also results in lower taxes, a minority can indirectly benefit from corruption even if it does not actually take part in it. In some cases, corruption can be prevented but its threat remains 
strong enough to alter the political equilibrium — and the ensuing allocation of resources — in a representative democracy.

These results depend on some critical assumptions, and further research is needed to test their robustness. In this model, public expenditure is entirely allocated to the purchase of a pure public good, all citizens earn the same gross income, and the latter is not affected by the tax level. It would be interesting to examine whether similar results could emerge in a general equilibrium model in which income, public expenditure, and taxes are all endogenously determined. The impact of any complementarity between public and private goods and the role of private enterprises in influencing the political equilibrium through corruption also deserve further analysis.

Some results could also be empirically tested. Cross-country studies based on corruption indices — such as those published by Transparency International or by the World Bank-and on an appropriate indicator of democracy could verify, for instance, whether corruption in democracy does actually result in a lower physical supply of public goods and lower taxes. The relation between trends in political preferences and the intensity of corruption could also be verified empirically.

New research could also explore the link between our results and some other previous findings. For instance, Mauro (1998) found evidence that corruption tends to reduce public expenditure on health and education in favor of items on which bribes can be more easily extracted; our theoretical results suggest that the public would vote to contain expenditure in the areas most affected by corruption. These results are not mutually exclusive, but a closer look into these issues could lead to interesting insights.

If further confirmed in future research, the results discussed above could bear important implications for the anticorruption efforts of the international community, including the mandate and policy advice of multilateral organizations such as the IMF and the World Bank. In some situations, domestic resistance to the fight against corruption is not limited to a comparatively small group of elected or appointed public officials but arises from a large number of nonelected citizens, most of whom are not directly involved in corruption. In such situations, technical improvements in specific legal or institutional aspects might not be sufficient to curb corruption and may not even be implemented unless supported by appropriate incentives. The international community could then be called to play the much more delicate — and controversial_-role of providing external economic and political incentives to reduce corruption. 


\section{Appendix: Proofs of Propositions}

\section{Proof of Proposition 1}

The citizens rank the corrupt candidates according to the policy $\tilde{g}$ that they implement once elected, which, to a nonelected citizen of type $\theta$, yields an indirect utility equal to $V^{C}(\tilde{g}, b ; \theta)$ (Figure 3). A citizen of generic type $\theta$ thus prefers a candidate of type $i$ to a candidate of type $j<i$ if and only if $V^{C}\left(\tilde{g}^{i}, b ; \theta\right)>V^{C}\left(\tilde{g}^{j}, b ; \theta\right)$, which implies $\theta>p^{*}\left(\tilde{g}^{i}-\tilde{g}^{j}\right) /\left\{n\left[u\left(\tilde{g}^{i}\right)-u\left(\tilde{g}^{j}\right)\right]\right\}$. The median voter is therefore pivotal in any pairwise choice among candidates. The candidate that is elected is therefore the candidate that, once elected, implements the policy choice of a nonelected median voter, that is, a candidate of some other type $\alpha$, such that $\tilde{g}^{\alpha}=\hat{g}^{\mu}$. This type is identified by $u^{\prime}\left(\tilde{g}^{\alpha}\right)=u^{\prime}\left(\hat{g}^{\mu}\right)=p^{*} /(n \alpha)=p /(n \mu)$, whence $\alpha=\left(p^{*} / p\right) \mu<\mu$.

Since $\alpha<\mu$, ceteris paribus, the elected candidate prefers a lower supply of roads than the median voter (and hence a majority of citizens): $\hat{g}^{\alpha}<\hat{g}^{\mu}$. Once elected, however, he sets the supply of roads equal to $\tilde{g}^{\alpha}=\hat{g}^{\mu}>g^{\mu}>\hat{g}^{\alpha}$, hence larger than the supply preferred by a majority in the absence of corruption. Q.E.D.

\section{Proof of Proposition 2}

A citizen of type $\theta$ prefers the equilibrium with corruption if and only if $V^{C}\left(\tilde{g}^{\alpha}, b ; \theta\right)>$ $V\left(g^{\mu} ; \theta\right)$, which yields:

$$
\theta<\theta^{O}(b) \equiv \frac{g^{\mu}-(1+b) \tilde{g}^{\alpha}}{n\left[u\left(g^{\mu}\right)-u\left(\tilde{g}^{\alpha}\right)\right]}
$$

(note that $u\left(g^{\mu}\right)>u\left(\tilde{g}^{\alpha}\right)$ because $\left.\tilde{g}^{\alpha}=\hat{g}^{\mu}<g^{\mu}\right)$. Some citizens therefore benefit from corruption if and only if $\theta^{0}(b)>\underline{\theta>0}$. If the Elasticity Condition fails, $\theta^{0}(b)$ is negative and therefore (by assumption) no citizen exists that prefers the equilibrium with corruption. If the Elasticity Condition holds, $\theta^{0}(b)$ is positive and the share of citizens who prefer the equilibrium with corruption is equal to $F\left(\theta^{0}(b)\right) \geq 0$, which is strictly positive if and only if $\theta^{0}(b)>\underline{\theta}$ By revealed preferences, these citizens are a minority “on the right” $\left(\theta^{0}(b)<\mu\right)^{42}$. Q.E.D.

\footnotetext{
${ }^{42}$ If they were a majority, in the absence of corruption they could elect a candidate of type $\zeta=\mu / p$, whose ideal policy $g^{\zeta}$ is equal to $\tilde{g}^{\alpha}$. This candidate would supply the same amount of roads that would be chosen in the equilibrium with corruption, but would impose lower taxes; hence, at least one outcome achievable without corruption is preferred by a majority of citizens to the equilibrium outcome with corruption. Since this outcome is not chosen in equilibrium, a fortiori the equilibrium outcome without corruption is preferred by a majority to the equilibrium with corruption.
} 


\section{Proof of Proposition 3}

When the median voter is corrupt, the latter (and hence a majority) prefers, among the set of honest candidates, the candidate whose type is closest to the median, which is a candidate of type $\theta^{*}(\pi)$ that has credibly signaled his honesty. ${ }^{43}$ If candidates of type $\alpha$ defined above are corrupt $(\alpha \leq \theta(\pi)$ ), by definition, the median voter prefers them to any other corrupt candidate; if they are honest, the median voter prefers, among the set of corrupt candidates, the candidate whose type is closest to $\alpha$, which is a candidate of type $\theta^{*}(\pi)$ that has signaled that he is corrupt. ${ }^{44}$

Let $g^{\gamma}$ denote the supply of roads preferred by an honest candidate of type $\theta^{*}(\pi)$ and assume first that $\alpha$ is corrupt. If $V\left(g^{\gamma} ; \mu\right)<V^{C}\left(\tilde{g}^{\alpha}, b ; \mu\right)$, the median voter (and hence a majority) prefers to elect the corrupt candidate $\alpha$, because the policy preferences of the "best" honest candidate $\theta^{*}(\pi)$ are too different from his own. In this case, a corrupt candidate is elected even if there are honest candidates available. If instead $V\left(g^{\gamma} ; \mu\right) \geq V^{C}\left(\tilde{g}^{\alpha}, b ; \mu\right)$, the median voter (and with him a majority) prefers to elect the honest candidate $\theta^{*}(\pi)$ that implements the policy $g^{\beta}$. In this case, corruption does not actually take place in equilibrium, but its threat-reflected in the reduction of the set of honest candidates $H(\pi)$-reduces the supply of roads from $g^{\mu}$ to $g^{\gamma}$ $<g^{\mu}$. Assume now that $\alpha$ is honest and let $\tilde{g}^{\gamma}$ be the policy choice adopted by a corrupt minister of type $\theta^{*}(\pi)$. In this case, the citizens elect either an honest candidate of type $\theta^{*}(\pi)$ or a corrupt candidate of the same type, depending on whether or not $V\left(g^{\gamma} ; \mu\right) \geq V^{C}\left(\tilde{g}^{\gamma}, b ; \mu\right)$. Q.E.D.

\section{Proof of Proposition 4}

If $\pi^{B}(\xi)<\pi^{v}$, the CMV maximizes his utility by setting $\pi=\pi^{v}$, hence $\theta^{*}(\pi)=v$. This decision ensures that honest candidates with the CMV's policy preferences exist at the political stage. Under this condition, one of these candidates is elected both in the progressive state (where they implement the PMV's ideal policy) and in the conservative state (where they are preferred to any corrupt candidate with policy preferences closer to the PMV's since, by assumption, $\pi^{B}(\xi)<\pi^{v}$ ). In the conservative state, however, the candidate elected is not the PMV and does not implement the ideal policy of the PMV but that of the CMV. Hence, in

\footnotetext{
${ }^{43}$ This follows from the fact that the utility perceived by the median voter when an honest candidate of type $\theta$ is elected—equal to $V\left(g^{\theta}, \mu\right)$-increases in $\theta$ when $\theta<\mu$ :

$$
V_{\theta}^{\prime}\left(g^{\theta} ; \mu\right)=\left[\mu u^{\prime}\left(g^{\theta}\right)-\frac{1}{n}\right] \frac{d g^{\theta}}{d \theta}=\frac{1}{n}\left(\frac{\mu}{\theta}-1\right) \frac{d g^{\theta}}{d \theta},
$$

which is positive if and only if $\theta<\mu$ since $d g^{\theta} / d \theta>0$. If the median voter is corrupt, $\theta^{*}(\pi)<\mu$ and hence $\theta<\mu$ for all honest candidates. The median voter's utility is thus maximized by electing the honest candidate with the largest value of $\theta$, which is an honest candidate of type $\theta^{*}(\pi)$.

${ }^{44}$ This follows from $V_{\theta}^{\prime}\left(\tilde{g}^{\theta} ; \mu\right)$ being negative if and only if $\theta>\alpha=\left(p^{*} / p\right) \mu$.
} 
the conservative state, corruption distorts the policy choice in favor of the CMV's preferences. Q.E.D.

\section{Proof of Proposition 5}

Let $\pi^{Z} \in\left[\pi^{B}(v), \pi^{v}\right]$ denote the value of $\pi$ such that $\pi \geq \pi^{B}(v)$ and $W\left(\pi^{Z}, v ; v\right)=W(0, v ; v)$ (which implies that, in the conservative state, the citizens elect an honest candidate which leaves the CMV weakly better off than in a corrupt equilibrium in which $\pi$ is set to zero), and let $\pi^{W}=\max \left(\pi^{Z}, \pi^{A}(\xi)\right)$ be the minimum value of $\pi$ that ensures the above outcome in the conservative state and the honesty of citizens of type $\alpha(\xi)$ in the progressive state. The CMV would not set $0<\pi<\pi^{W}$, since his utility in both states of the world would be at least equally large if he set either $\pi=0$ or $\pi=\pi^{W}{ }^{45}$ In addition, the CMV would not set $\pi>\pi^{v}$ since $W(\pi, v ; v)=W\left(\pi^{v}, v ; v\right)$ for all $\pi>\pi^{v}$ in the conservative state (the citizens always elect the honest PMV), but $W(\pi, \xi ; v)<W\left(\pi^{v}, \xi ; v\right)$ for all $\pi>\pi^{v}$ in the progressive state. ${ }^{46}$

Hence, the CMV sets $\pi$ either at a level equal to 0 (in which case corruption is fully permitted in both states, and the citizens elect a corrupt candidate of type $\alpha(v)$ in the conservative state and of type $\alpha(\xi)$ in the progressive state) or at some positive level in the interval $\left[\pi^{W}, \pi^{v}\right]$.

In this interval, the CMV's utility increases in $\pi$ in the conservative state and diminishes in the progressive state. The value of $\pi$ that maximizes the CMV's expected utility varies

\footnotetext{
${ }^{45}$ In the conservative state, the CMV's utility is equal to $W(\pi, v ; v) \leq W\left(\pi^{Z}, v ; v\right)=W(0, v ; v)$, by definition, for all positive $\pi \leq \pi^{Z}$, and is at least as large if $\pi$ is set instead equal to 0 . In the progressive state the CMV's utility is equal to $W(\pi, \xi ; v)=W\left(\pi^{A}(\xi), \xi ; v\right)=W(0, \xi ; v)$ whenever $\pi \leq \pi^{A}(\xi)$ (in which case the citizens elect a corrupt candidate of type $\alpha(\xi)$, as they do when $\pi=0$ ) and is equal to $W(\pi, \xi ; v)<W\left(\pi^{A}(\xi), \xi ; v\right)$ whenever $\pi^{A}(\xi)<\pi<\pi^{Z}$ $<\pi^{B}(\xi)$ (in which case the citizens elect a corrupt candidate of type $\theta^{*}(\pi)>\alpha(\xi)$ that is less preferred by the CMV than a candidate of type $\alpha(\xi)$ ). The CMV's expected utility is therefore larger if he sets $\pi=0$ than if he sets $\pi$ at any positive level below $\pi^{Z}$. Note that $\pi^{Z}<\pi^{B}(\xi)$ follows from the assumption that $\pi^{v}<\pi^{B}(\xi)$.

${ }^{46}$ In the progressive state, the CMV's utility is diminishing in the interval $\left[\pi^{A}(\xi), \pi^{B}(\xi)\right]$ (which includes $\pi^{v}$ ), where higher levels of $\pi$ induce the election of a corrupt citizen whose type is more distant from $\alpha(v)$ and who therefore implements a policy less preferred by the CMV. The CMV's utility also diminishes in $\pi$ in the interval $\left[\pi^{B}(\xi), \pi^{\xi}\right]$, where higher levels of $\pi$ induce the election of an honest citizen whose type is more distant from the CMV's. At $\pi=\pi^{B}(\xi)$, the CMV's utility increases discontinuously, from $V^{C}\left(\tilde{g}^{\theta^{*}\left(\pi^{B}(\xi)\right)}, b ; v\right)<V^{C}\left(\tilde{g}^{v}, b ; v\right) \equiv W\left(\pi^{v}, \xi ; v\right)$ to $V\left(g^{\theta^{*}\left(\pi^{B}(\xi)\right)} ; v\right) \equiv W\left(\pi^{B}(\xi), \xi ; v\right)$. Since by assumption $W\left(\pi^{B}(\xi), \xi ; v\right)<W\left(\pi^{v}, \xi ; v\right)$ then $W(\pi, \xi ; v)<W\left(\pi^{v}, \xi ; v\right)$ in the interval $\left[\pi^{v}, \pi^{\xi}\right]$ in the progressive state.
} 
continuously in $q .{ }^{47}$ If $\pi^{A}(\xi)>\pi^{Z}$, for sufficiently low values of $q$, the CMV prefers to set $\pi=0$ (and elect a corrupt candidate in both states of the world) than to set $\pi^{Z}<\pi<\pi^{A}(\xi)$ and risk a less favorable outcome if the progressive state occurs. ${ }^{48}$ If instead $\pi^{A}(\xi)<\pi^{Z}$ (and hence $\pi^{W}=\pi^{Z}$ ), then the CMV does not set $\pi=0$, as it is always convenient for him to set $\pi$ at least equal to $\pi^{A}(\xi)$. If $\pi=\pi^{A}(\xi)$ the CMV obtains exactly the same utility as if $\pi=0$ in the progressive state, but in the conservative state he gets a larger utility, because $\pi^{A}(\xi)>\pi^{Z}$. In this case, law enforcement is always sufficiently strong to prevent corruption in the conservative state, irrespective of the probability of the latter. Q.E.D.

\footnotetext{
${ }^{47}$ When $\pi^{W}<\pi<\pi^{v}$, in the conservative state, the citizens elect an honest candidate of type $\theta^{*}(\pi)<v$ and the CMV's utility is equal to $W(\pi, v ; v)=V\left(g^{\gamma} ; v\right)$, which is continuous and differentiable in $\pi$, with $W^{\prime}{ }_{\pi}(\pi, v ; v)=$ $V^{\prime}{ }_{\pi}\left(g^{\gamma} ; v\right) d g^{\gamma} / d \theta^{*}(\pi) d \theta^{*}(\pi) / d \pi$ continuous and positive (since $V\left(g^{\gamma} ; v\right)$ is increasing in $\theta^{*}(\pi)$ for $\left.\theta^{*}(\pi)<v\right)$. In the progressive state, the citizens elect a corrupt candidate of type $\theta^{*}(\pi)>\alpha(\xi)$ and the CMV's utility is equal to $W(\pi, \xi ; v)=V^{C}\left(\tilde{g}^{\gamma}, b ; v\right)$, which is continuous and differentiable in $\pi$ with $W_{\pi}^{\prime}(\pi, \xi ; v)=V^{C},{ }_{\pi}\left(\tilde{g}^{\gamma}, b ; v\right) d \tilde{g}^{\gamma} / d \theta^{*}(\pi)$ $d \theta^{*}(\pi) / d \pi$ continuous and negative (since $V^{C}\left(\tilde{g}^{\gamma}, b ; v\right)$ is diminishing in $\theta^{*}(\pi)$ for $\left.\theta^{*}(\pi)>\alpha\right)$. Hence, $W^{E}(\pi, q ; v)=$ $q W(\pi, v ; v)+(1-q) W(\pi, \xi ; v)=q V\left(g^{\gamma} ; v\right)+(1-q) V^{C}\left(\tilde{g}^{\gamma}, b ; v\right)$ is continuous and differentiable in $q$ and $\pi$, with $W^{E}{ }_{q}(\pi, q ; v)=V\left(g^{\gamma} ; v\right)-V^{C}\left(\tilde{g}^{\gamma}, b ; v\right)>0$ and $W^{E},{ }_{\pi}(\pi, q ; v)=q W^{\prime}{ }_{\pi}(\pi, v ; v)+(1-q) W^{\prime}{ }_{\pi}(\pi, \xi ; v)$. Let $\pi^{*}(q)$ be the value of $\pi$ that maximizes $W^{E}$ given $q$ (solving $W^{E}{ }_{\pi}\left(\pi^{*}, q ; v\right)=0$ ); this value is continuous in $q$ since $W^{E}$, ${ }_{\pi}(\pi, q ; v)$ is continuous in both $\pi$ and $q$.

${ }^{48}$ If $\pi^{Z}(v)<\pi<\pi^{A}(\xi)$, the CMV's expected utility is equal to $W^{E}(\pi, q ; v) \equiv q W(\pi, v ; v)+(1-q) W(\pi, \xi ; v)=$ $q V\left(g^{\gamma}, v\right)+(1-q) V^{C}\left(\tilde{g}^{\gamma}, b ; v\right)$. If $\pi=0$, the CMV's utility is equal to $W^{E}(0, q ; v) \equiv q W(0, v ; v)+(1-q) W(0, \xi ; v)=$ $q V\left(\tilde{g}^{\alpha(v)}, b ; v\right)+(1-q) V^{C}\left(\tilde{g}^{\alpha(\xi)}, b ; v\right)$. Both $W^{E}(\pi, q ; v)$ and $W^{E}(0, q ; v)$ are continuous and diminishing in $q$, with $\lim _{q \rightarrow^{0}} W^{E}(\pi, q ; v)=V^{C}\left(\tilde{g}^{\gamma}, b ; v\right)<\lim _{q_{\rightarrow} 0} W^{E}(0, q ; v)=V^{C}\left(\tilde{g}^{\alpha(\xi)}, b ; v\right)$. If $q$ is sufficiently low, therefore, the CMV's expected utility is larger when $\pi$ is set equal to 0 .
} 


\section{REFERENCES}

Ades, Alberto; and Di Tella, Rafael (1997) "National Champions and Corruption: Some Unpleasant Interventionist Arithmetic,” Economic Journal 107 (7), pp. 1023-42.

Allen, R.D.G.; and Lerner, A.P. (1934) “The Concept of Arc Elasticity of Demand,” The Review of Economic Studies 1 (3), pp. 226-30.

Barro, Robert (1973) “The Control of Politicians: An Economic Model,” Public Choice 14 (1), pp. 19-42.

Basu, Kaushik; Bhattacharya, Sudipto; and Mishra, Ajit (1992) "Notes on Bribery and the Control of Corruption,” Journal of Public Economics 48 (3), pp. 349-59.

Becker, Gary S. (1968) “Crime and Punishment: An Economic Approach,” Journal of Political Economy 76 (2), pp. 169-217.

Becker, Gary S. (1983) "A Theory of Competition Among Pressure Groups for Political Support,” Quarterly Journal of Economics 98 (3), pp. 371-400.

Beenstock, Michael (1979) “Corruption and Development,” World Development 7 (1), pp. 15-24.

Bernhard, William (2002) Banking on Reform: Political Parties and Central Bank Independence in the Industrial Economies, The University of Michigan Press, pp. xiv, 237.

Besley, Timothy; and Coate, Stephen (1997) "An Economic Model of Representative Democracy,” Quarterly Journal of Economics 112 (1), 85-114.

Besley, Timothy; and McLaren, John (1993) "Taxes and Bribery: The Role of Wage Incentives,” Economic Journal 103 (416), pp. 119-41.

Calderon, César; and Chong, Alberto (2006) "Do Democracies Breed Rent-Seeking Behavior?” The Journal of Policy Reform 9 (4), pp. 247-60.

Chander, Parkash; and Wilde, Louis (1992) "Corruption in Tax Administration," Journal of Public Economics 49 (3), pp. 333-49.

Del Monte, Alfredo; and Papagni, Erasmo (2001) "Public Expenditure, Corruption, and Economic Growth: The Case of Italy,” European Journal of Political Economy 17 (1), pp. 1-16.

Dudley, Leonard; and Montmarquette, Claude (1987) "Bureaucratic Corruption as a Constraint on Voter Choice,” Public Choice 55 (1-2), pp. 127-60. 
Galeotti, Gianluigi; and Merlo, Antonio (1994) "Political Collusion and Corruption in a Representative Democracy,” Public Finance-Finances Publiques 49 (Suppl.) pp. 232-43.

Grossman, Gene M.; and Helpman, Elhanan (1996) "Electoral Competition and Special Interest Politics,” Review of Economic Studies 63 (2), pp. 265-86.

Gupta, Sanjeev; Davoodi, Hamid R.; and Alonso-Terme, Rosa (2002) "Does Corruption Affect Income Inequality and Poverty?” Economics of Governance, 3 (1), pp. 23-45.

Hindricks, Jean; Keen, Michael; and Muthoo, Abhinat (1999) "Corruption, Extortion, and Evasion,” Journal of Public Economics 74 (3), pp. 395-430.

Johnson, Otmunde E. G. (1975) "An Economic Analysis of Corrupt Government, With Special Applications to Less Developed Countries,” Kyklos 28 (1), pp. 47-61.

Kurer, Oskar (2001) “Why Do Voters Support Corrupt Politicians?” in: Jain, Arvind K. (ed.) The Political Economy of Corruption, London, Routledge, pp. 63-86.

Mauro, Paolo (1995) “Corruption and Growth,” Quarterly Journal of Economics, 110 (3), pp. 681-712.

Mauro, Paolo (1998) "Corruption and the Composition of Government Expenditure," Journal of Public Economics, 69 (2), pp. 263-79.

McGregor, Rob Roy (2007) "Federal Reserve Transparency: The More Things Change, The More They Stay The Same?” Public Choice 133 (3-4), pp. 269-73.

Mookherjee, Dilip; and Png, I. P. L. (1995) “Corruptible Law Enforcers: How Should They Be Compensated?” Economic Journal 105 (428), pp. 145-59.

Myerson, Roger B. (1993) "Effectiveness of Electoral Systems for Reducing Government Corruption: A Game Theoretic Analysis," Games and Economic Behavior 5 (1), pp. 118-32.

Osborne, Martin J.; and Slivinski, Al (1996) "A Model of Political Competition with CitizenCandidates,” Quarterly Journal of Economics 111 (1), 65-96.

Paldam, Martin (2002) "The Cross-Country Pattern of Corruption: Economics, Culture and the Seesaw Dynamics," European Journal of Political Economy, 18 (2), pp. 215-40.

Persson, Torsten; Tabellini, Guido; and Trebbi, Francesco (2003) "Electoral Rules and Corruption,” Journal of the European Economic Association, 1 (4), pp. 958-89. 
Peters, John G.; and Welch, Susan (1980) "The Effects of Charges of Corruption on Voting Behavior in Congressional Elections,” American Political Science Review 74 (3), pp. 697-708.

Rose-Ackerman, Susan (1975) “The Economics of Corruption,” Journal of Public Economics 4 (2), pp. 187-203.

Rose-Ackerman, Susan (1978) Corruption: A Study in Political Economy, New York, Academic Press, pp. xii, 258.

Rose-Ackerman, Susan (1999) Corruption and Government : Causes, Consequences, and Reform, Cambridge, U.K., Cambridge University Press, pp. xiii, 266.

Rundquist, Barry S.; Strom, Gerald S.; and Peters, John G. (1977) "Corrupt Politicians and Their Electoral Support: Some Experimental Observations,” American Political Science Review 71 (3), pp. 954-63.

Shleifer, Andrei; and Vishny, Robert W. (1993) “Corruption,” Quarterly Journal of Economics 108 (3), pp. 599-617.

Tanzi, Vito; and Davoodi, Hamid R. (1998) “Corruption, Public Investment and Growth,” in: Shibata, Hirofumi; and Ihori, Toshihiro (eds.) The Welfare State, Public investment, and Growth: Selected Papers from the 53rd Congress of the International Institute of Public Finance, Tokyo, Springer-Verlag, pp. 41-60.

Treisman, Daniel (2000) “The Causes of Corruption: A Cross-National Study,” Journal of Public Economics 76 (3), pp. 399-457.

van Winden, Frans (1999) "On the Economic Theory of Interest Groups: Toward a Group Frame of Reference in Political Economics,” Public Choice 100 (1-2), pp. 1-29. 